\title{
Fatores associados à distribuição da temperatura das superfícies em áreas urbanas: zonas climáticas locais e características espectrais
}

\author{
Land surface temperature associated factors in urban \\ areas: local climate zones and spectral characteristics
}

\author{
Fabiana Lourenço e Silva Ferreira \\ Enio Bueno Pereira \\ Lucila Chebel Labaki
}

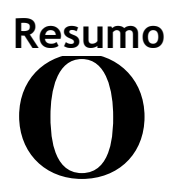

negativa do sistema climático urbano naturalmente. O método contempla o uso de imagens Landsat-8, para estimar e mapear a temperatura das superfícies e suas características espectrais (albedo, emissividade, fração de cobertura de vegetação e índice de umidade por diferença normalizada), a integração dos dados em um espaço celular georreferenciado, análises de correlação, autocorrelação e de clusters, e identificação de zonas climáticas locais. A área de estudos é São José dos Campos, SP, Brasil, onde a zona climática local 3, com construções compactas de pequeno porte, é predominante. A maior diferença de temperatura de superfície entre clusters foi $12{ }^{\circ} \mathrm{C}$ e ocorreu entre áreas verdes e permeáveis e áreas áreas plenamente impermeabilizadas com extensas construções. As análises permitiram inferir a dependência espacial da temperatura da superfície, apesar da variabilidade sazonal, indicando que ela pode ser utilizada para identificar fatores que influenciam processos de retroalimentação do sistema climático urbano, zonas climáticas locais, e auxiliar no desenvolvimento de políticas de adaptação e resiliência urbana ao calor.

Palavras-chave: Política urbana. Temperatura das superfícies. Zonas climáticas locais. Benchmarking.

\section{Abstract}

Global warming makes urban fabric benchmarking necessary for the development of policies that promote urban heat resilience. This research is aimed at identifying urban fabric patterns, which can promote the negative feedback of the

${ }^{1}$ Fabiana Lourenço e Silva Ferreira ${ }^{1}$ Instituto Nacional de Pesquisas Espaciais São José dos Campos - SP - Brasil

${ }^{2}$ Enio Bueno Pereira ${ }^{2}$ Instituto Nacional de Pesquisas Espaciais

${ }^{3}$ Lucila Chebel Labaki ${ }^{3}$ Universidade Estadual de Campinas Campinas - SP - Brasil

Recebido em 06/12/19 Aceito em 04/05/20 urban climate system naturally. The method includes the use of Landsat-8 satellite images to estimate and to map the land surface temperatures and its spectral features (albedo, emissivity, fraction vegetation cover and normalised difference moisture index), the data integration at a cellular georeferenced space, correlation, autocorrelation and clusters analyses and the identification of local climate zones. The study area is São José dos Campos, SP, Brazil, where local climate zone 3, where compact, small buildings predominate. The biggest difference in surface temperature was $12^{\circ} \mathrm{C}$ and was detected between areas with permeable and shaded surfaces, associated with the presence of trees, and fully impermeable surfaces with large buildings. The analyses showed the spatial dependence of surface temperature, despite seasonal variability, indicating that it can be used to identify factors which influence feedback processes of the urban climate system, which can help in the development of policies to promote urban adaptation and heat resilience.

Keywords: Urban policy. Land surface temperature. Local climate zones. Benchmarking. 


\section{Introdução}

O planeta já aqueceu mais de $1{ }^{\circ} \mathrm{C}$ em relação ao período pré-industrial. O desafio é limitar o aquecimento global em $1,5^{\circ} \mathrm{C}$ até 2050 , conforme definido na $21^{\circ}$ Conferência das Nações Unidas (COP 21) ou acordo de Paris, realizada em 2015. Para isso as emissões de gases de efeito estufa relativas ao estoque de edifícios no mundo precisam ser reduzidas entre 80-90\% em relação ao ano de 2010 (ALLEN; DUBE; SOLECKI, 2018).

A redução das emissões referentes aos edifícios está relacionada às mudanças de hábitos, de consumo e estilo de vida da população urbana, bem como à implementação de tecnologias construtivas mais eficientes, incorporando a utilização de métodos baseados na natureza, que podem e devem ser integradas às leis urbanísticas que ordenam o crescimento das cidades. A política urbana pode servir como um acelerador no processo de transição dos sistemas que integram o meio ambiente urbano, visto que as cidades são polo de desenvolvimento tecnológico e disseminação de novas ideias e tecnologias (BAZAZ et al., 2019).

Nas cidades as altas temperaturas e a baixa qualidade do ar resultantes da formação das ilhas de calor urbanas (ICU), em ocorrência simultânea às ondas de calor, colocam em risco a saúde humana, afetam o bem-estar e a produtividade da população urbana, que recorre a sistemas para climatização artificial. As ICU interferem na dinâmica dos sistemas ambientais alterando o balanço de energia no espaço urbano e adjacente e provocando desconforto térmico na população urbana dentro e fora das edificações, induzindo ao aumento do uso de sistemas de climatização artificial para resfriamento e refrigeração, nos edifícios e meios de transporte.

O calor retirado dos ambientes internos, por sistemas mecanizados, e a poluição gerada pela demanda de energia do processo de climatização retornam então às áreas externas, amplificando as temperaturas no ambiente e consequentemente a demanda de energia para climatização, produzindo assim um efeito de retroalimentação positiva do sistema. Nos processos de retroalimentação positiva, uma parte da saída da ação de um sistema retorna para a entrada, realimentando o sistema e atuando para estimular ainda mais o processo. No caso de retroalimentação negativa, parte da produção é subtraída da entrada e atua para mitigar o fenômeno (MCGUFFIE; HENDERSON-SELLERS, 2018).

O resfriamento natural das superfícies urbanas, principalmente em países de clima predominantemente tropical como o Brasil, pode ser utilizado para produzir o efeito de retroalimentação negativa do sistema climático urbano. A retroalimentação negativa do sistema climático urbano consiste na atenuação do calor, que melhora o desempenho térmico e energético das áreas urbanas, o que deve ser feito sem comprometer o conforto ambiental considerando a variabilidade sazonal climática.

Entre os benefícios diretos e indiretos alcançados pela redução da temperatura das superfícies urbanas estão: o aumento do conforto térmico humano nas cidades (dada a redução das temperaturas), a melhora da qualidade do ar (dada a redução dos efeitos fotoquímicos que elevam os níveis de ozônio na superfície $\left(\mathrm{O}_{3}\right)$ ), a redução do consumo de energia para o resfriamento de ar no verão em edificações (dada a diminuição da carga térmica absorvida pelas edificações) e a redução da demanda de geração de energia elétrica e emissões de gases de efeito estufa relacionadas (AKBARI et al., 2015).

O resfriamento das superfícies urbanas pode ser alcançado através da implementação de tecnologias solares passivas (TSP), que consideram os serviços ecossistêmicos e as características espectrais dos componentes da paisagem, que afetam o balanço de energia nas superfícies e determinam o saldo da radiação solar absorvida, que é transformada em calor.

As tecnologias passivas, voltadas para o resfriamento dos centros urbanos, utilizam os conceitos de infraestruturas "verdes", "azuis" e "cinza". Esses conceitos contemplam técnicas construtivas desenvolvidas para promover a sustentabilidade em áreas urbanas. As infraestruturas "verdes" e "azuis" preconizam a utilização dos serviços ecossistêmicos da vegetação e da água no ambiente, para promover o resfriamento das áreas urbanas, o sequestro de carbono e a sustentabilidade nas cidades. As infraestruturas "cinza", por sua vez, preconizam o uso de materiais e sistemas construtivos que consideram as características espectrais dos elementos da paisagem urbana, para melhorar o desempenho térmico e energético das área urbanas (QI et al., 2019).

Este trabalho tem o objetivo de identificar padrões do tecido urbano que produzem a retroalimentação negativa do sistema climático urbano naturalmente. 


\section{Cidades no contexto das mudanças climáticas}

As cidades são consideradas pontos-chave ou "hot spots" para minimizar o impacto antrópico no clima planetário. Embora representem somente $2 \%$ da superfície do planeta, são responsáveis pelo consumo de $75 \%$ de toda energia produzida e geram aproximadamente $55 \%$ dos gases de efeito estufa devido à demanda de energia produzida por combustíveis fósseis (URBANIZATION..., 2016).

O estilo de vida urbano reflete em como a energia é consumida no mundo: em 2005 os três setores que mais demandaram energia foram os edifícios (34\%), transportes $(28 \%)$ e indústrias $(27 \%)$. Dos $34 \%$ da energia demandada pelos edifícios aproximadamente $25 \%$ foram utilizados para a climatização artificial, dependendo do uso que se faz da edificação e da região geográfica em que se encontra (GLOBAL ENERGY..., 2020).

A previsão de crescimento do uso de energia para climatização dos edifícios é de $79 \%$ para o setor residencial e $84 \%$ para o setor comercial no período de 2010 a 2050, sendo que para a maioria das cidades a demanda de energia para resfriamento de ar no verão irá exceder a demanda para aquecimento no inverno (LUCON et al., 2018). Além disso, o crescente uso de condicionadores de ar em todo o mundo será uma das principais demandas de eletricidade nas próximas três décadas, principalmente em países situados em regiões mais quentes (INTERNATIONAL..., 2020).

As ilhas de calor urbanas (ICU) ocorrem em diferentes escalas e dimensões: horizontal, vertical e temporal e originam-se a partir da absorção da radiação solar pelas superfícies e pelo calor antropogênico, fenômenos que podem ser descritos através da evolução da temperatura das superfícies (TS) (OKE, 1982).

Os avanços nos estudos sobre climatologia urbana, que extrapolaram a classificação urbano-rural, iniciaramse na década de 60, quando foram realizados estudos baseados na classificação das cidades por zonas climáticas em função de padrões da paisagem urbana, visto que a diferenciação pura e simples entre "urbano" e "rural" é limitada e incapaz de representar as diversas configurações da paisagem urbana. O conceito de zonas climáticas locais (ZCL) consiste no agrupamento de regiões homogêneas cuja estrutura da superfície é uniforme e se propaga na escala horizontal local (que abrange centenas de metros a quilômetros de distância). A classificação das zonas climáticas locais (ZCLs) é feita a partir de 17 classes. Em 10 delas a classificação é feita a partir da estrutura do tecido urbano: tipologia construtiva, forma e distribuição das edificações, e em 7 a classificação é feita a partir das características da cobertura do solo: água, árvores densas, árvores esparsas, solo exposto, tipos de pavimentos, entre outros (Figura 1) (STEWART; OKE; KRAYENHOFF, 2014).

Os sistemas de zoneamento climático têm várias aplicações e vêm sendo cada vez mais utilizados como base para o desenvolvimento de programas para melhorar a eficiência energética em edificações e cidades, o que vem ocorrendo com mais frequência nos últimos 15 anos. As variáveis mais utilizadas em programas de eficiência energética para fins de zoneamento climático são: temperatura, graus-dia, altitude e umidade relativa do ar (WALSH; CÓSTOLA; LABAKI, 2017).

\section{Tecnologias solares passivas (TSP) para promover naturalmente o resfriamento de áreas urbanas}

As TSP contemplam estratégias e técnicas que não utilizam meios mecânicos artificiais ou que demandam energia para seu funcionamento (MOITA, 2010). Em áreas urbanas as TSP utilizadas para promover a eficiência térmica e energética contemplam o uso da vegetação e de materiais ou superfícies denominadas "frias" em coberturas e pavimentos urbanos (AKBARI et al., 2015).

As TSP utilizadas em áreas urbanas também são denominadas infraestruturas "verdes", "azuis" e "cinza". Entre os benefícios que se pode alcançar com a sua utilização, pode-se citar a ampliação da resiliência urbana frente ao aumento das temperaturas, bem como o controle de enchentes, a alimentação de lençóis freáticos, a melhora da qualidade do ar e da água, e a atenuação das ICU, entre outros fatores que remetem à qualidade de vida nas cidades e à saúde humana (QI et al., 2019).

As infraestruturas "verdes" consistem em superfícies naturais vivas, compostas por vegetação; podem ser implementadas através de áreas, telhados e muros verdes, florestas urbanas, entre outros. A vegetação promove o resfriamento pela sua capacidade de absorção de radiação solar no intervalo do visível, pelo sombreamento e pela promoção dos fluxos de calor latente, associados aos processos de evapotranspiração das plantas e presença de umidade. Sua utilização favorece também a redução dos índices de poluição do ar e o sequestro de carbono. As infraestruturas "azuis" consistem em áreas alagadas, rios, lagos e espelhos de 
água. A água é a substância terrestre com o maior calor específico, o que lhe garante alta capacidade de armazenamento de calor; também contribui para a promoção dos fluxos de calor latente, em que o calor é retirado do ar no processo de evaporação. As infraestruturas "cinza" consistem em infraestruturas artificiais criadas pelo homem; podem ser utilizadas para regular os fluxos de calor em áreas urbanas, através da ampliação de seu desempenho térmico, pela redução de sua temperatura, pelo aumento de seu albedo e capacidade de estocar calor (QI et al., 2019).

Alguns materiais permanecem mais frios que outros quando expostos à mesma intensidade de radiação solar; são os chamados materiais "frios". Esses materiais são caracterizados por apresentar alto albedo e emissividade. Possuem maior capacidade de refletir a radiação solar ou radiação de onda curta, que sobre eles incide, e emitir a radiação de onda longa ou radiação infravermelha (GLOBAL COOL..., 2020).

Figura 1 - Zonas climáticas locais (ZCLs)

\begin{tabular}{|c|c|c|c|}
\hline $\mathrm{ZCL1}$ & $\begin{array}{l}\text { Ocupações compactas } \\
\text { com edificações } \\
\text { verticais de grande } \\
\text { porte (gabarito } \\
\text { elevado). }\end{array}$ & ZCL2 & $\begin{array}{l}\text { Ocupações compactas com } \\
\text { edificações de médio porte } \\
\text { (gabarito médio) }\end{array}$ \\
\hline ZCL3 & $\begin{array}{l}\text { Ocupações compactas } \\
\text { com edificações de } \\
\text { pequeno porte } \\
\text { (gabarito baixo) }\end{array}$ & ZCL4 & $\begin{array}{l}\text { Ocupações esparsas com } \\
\text { edificações verticais } \\
\text { (gabarito elevado) } \\
\text { intercaladas por vegetação }\end{array}$ \\
\hline ZCL5 & $\begin{array}{l}\text { Ocupações esparsas } \\
\text { com edificações de } \\
\text { médio porte (gabarito } \\
\text { médio) intercaladas } \\
\text { por vegetação }\end{array}$ & ZCL6 & $\begin{array}{c}\text { Ocupações esparsas com } \\
\text { edificações de pequeno } \\
\text { porte (gabarito baixo) } \\
\text { intercaladas por vegetação }\end{array}$ \\
\hline ZCL7 & $\begin{array}{l}\text { Ocupações compactas } \\
\text { com edificações leves } \\
\text { de pequeno porte } \\
\text { (baixo gabarito) }\end{array}$ & ZCL8 & $\begin{array}{l}\text { Ocupações esparsas com } \\
\text { edificações de extensas de } \\
\text { médio porte (gabarito } \\
\text { médio) em áreas } \\
\text { predominantemente } \\
\text { impermeabilizadas }\end{array}$ \\
\hline ZCL9 & $\begin{array}{l}\text { Ocupações esparsas } \\
\text { em áreas } \\
\text { predominantemente } \\
\text { permeáveis }\end{array}$ & ZCL10 & $\begin{array}{c}\text { Ocupações com } \\
\text { edificações industriais }\end{array}$ \\
\hline onswow & $\begin{array}{c}\text { Cobertura: } \\
\text { arvores densas }\end{array}$ & 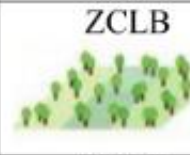 & $\begin{array}{c}\text { Cobertura: } \\
\text { árvores esparsas }\end{array}$ \\
\hline $\begin{array}{c}\text { ZCLC } \\
x^{2}+x^{2}+x^{2}+x^{2}+t^{2}\end{array}$ & $\begin{array}{l}\text { Cobertura: } \\
\text { mato ou arbusto }\end{array}$ & ZCLD & $\begin{array}{c}\text { Cobertura: } \\
\text { pasto ou vegetação de } \\
\text { pequeno porte }\end{array}$ \\
\hline ZCLE & $\begin{array}{c}\text { Cobertura: } \\
\text { pavimento ou pedra }\end{array}$ & ZCLF & $\begin{array}{l}\text { Cobertura: } \\
\text { solo exposto ou areia }\end{array}$ \\
\hline$\therefore$ & $\begin{array}{l}\text { Cobertura: } \\
\text { água }\end{array}$ & & \\
\hline
\end{tabular}

Fonte: adaptado de Stewart, Oke e Krayenhoff (2014). 
Em geral o albedo elevado dos materiais é imputado a cores claras, porém somente a cor clara não é indicativa de albedo elevado. As cores claras indicam maior refletância no intervalo da radiação solar visível, que representa cerca de $46 \%$ da radiação solar que atinge a superfície terrestre, porém o albedo também é resultado da refletância no infravermelho próximo, que representa aproximadamente $43 \%$. Resultados de medições de albedo de materiais utilizados em coberturas no Brasil, utilizando um espectrofotômetro com esfera integradora, mostram que a cerâmica vermelha, por exemplo, apresentou refletância em torno de $33 \%$ no visível e $78 \%$ no infravermelho próximo, o que lhe conferiu uma refletância total ou albedo de aproximadamente $67 \%$, enquanto telhas de cimento colorido cinza claro e as de fibrocimento apresentam refletância em torno de $34 \%$ para o visível e $37 \%$ no infravermelho próximo, com uma refletância total em torno de 36\%. Sendo assim, a cerâmica vermelha tem maior potencial de resfriamento quando exposta à mesma quantidade de radiação solar que os demais materiais (PRADO; FERREIRA, 2005).

A emissividade ou emitância térmica de uma superfície consiste na capacidade da superfície emitir radiação térmica, o que lhe garante maior capacidade de resfriamento. Os materiais metálicos, por exemplo, têm alto albedo, porém baixa capacidade de emitir radiação térmica, levando-os a permanecer mais quentes que os não metálicos, mesmo com menor albedo (GLOBAL COOL..., 2020).

As estratégias para promover a redução das temperaturas no meio ambiente urbano devem estar associadas às características climáticas e construtivas locais, sendo essenciais para a preservar a saúde e a qualidade de vida nas cidades nos períodos de calor excessivo, bem como promover a eficiência energética em edificações.

\section{Método}

O método contempla a criação de um modelo espacialmente explícito, criado para representar unidades territoriais urbanas, considerando-se a dependência espacial da temperatura das superfícies. Os modelos espacialmente explícitos são ferramentas que auxiliam no entendimento dos padrões de mudança de uso e cobertura do solo, são análogos à ecologia da paisagem, e enfocam a estrutura que estabelece relações espaciais entre os componentes da paisagem (CHUVIECO; HUETE, 2010). As relações espaciais são estabelecidas a partir do conceito de dependência espacial, partindo do princípio de que as ocorrências sociais e ambientais se dão de acordo com a distância (TOBLER, 1979). Permitem integrar informações multidisciplinares em diferentes escalas de espaço e tempo e aferir dados de ordem qualitativa e quantitativa (VERBURG et al., 1999). Nesse tipo de modelo o espaço geográfico é representado por uma grade regular ou espaço celular (CS), e cada região da superfície é associada a um atributo, o que permite estabelecer a relação entre o fenômeno de estudo e os padrões associados ao espaço (DRUCK et al., 2004).

As variáveis ou características espectrais, utilizadas para compor o modelo espacialmente explícito, foram estimadas por sensoriamento remoto. As variáveis foram escolhidas considerando-se os fatores que influenciam o balanço de energia nas superfícies:

(a) fração de cobertura de vegetação (FCV), utilizada para representar a vegetação e os processos de resfriamento associados: sombreamento, evapotranspiração e permeabilidade do solo;

(b) emissividade $(\mathcal{E})$ para representar os processos de emissão de radiação de onda longa, em função de sua temperatura;

(c) albedo (A) para representar a capacidade de uma superfície refletir radiação de onda curta ou radiação solar;

(d) índice de umidade por diferença normalizada (NDMI), utilizado para representar a presença de água na superfície e áreas permeáveis; e

(e) temperatura das superfícies (TS), para representar o saldo de energia resultante da interação das variáveis espectrais.

O sistema de classificação utilizado para representar os padrões da paisagem urbana foi baseado nas zonas climáticas locais (ZCL) (STEWART; OKE, 2012; STEWART; OKE; KRAYENHOFF, 2014).

As bases de dados utilizadas foram:

(a) Serviço Geológico Americano (USGS), onde foram obtidas as imagens do satélite Landsat-8 da coleção Nível 2 (L8-L2) (UNITED..., 2019a, 2019b, 2019c); 
(b) o banco de dados da Empresa Ambiental do Estado de São Paulo (CETESB) (COMPANHIA..., 2018) e o banco de dados climatológicos do comando da aeronáutica (REDEMET, 2018) de onde foram tiradas as informações sobre temperatura do ar $\left(\right.$ Tar em $\left.{ }^{\circ} \mathrm{C}\right)$ na hora da aquisição das imagens; e

(c) o acervo de mapas, imagens e leis da Prefeitura Municipal de São José dos Campos (PREFEITURA..., 2019a).

Os softwares utilizados foram: QGIS, sistema de informação geográfica (SIG) (QGIS, 2017), o "Fillcell" gerenciador de scripts utilizado para a construção do CS e preenchimento de células compatível com os programas desenvolvidos pelo Instituto Nacional de Pesquisas Espaciais (INPE) (INSTITUTO..., 2018), o (3) GeoDa (GEODA, 2019) e o R Studio (RSTUDIO, 2015). Todos softwares gratuitos de código aberto.

O método utilizado para atingir os objetivos desta pesquisa contempla três etapas:

(a) estimar e mapear as características espectrais e temperatura da superfície por sensoriamento remoto, utilizando produtos da coleção Landsat-8 Nível 2 (L8-L2), e integrar os resultados no espaço celular criado para representar a área de estudos;

(b) verificar os resultados obtidos por sensoriamento remoto, comparando-se os resultados obtidos nesta pesquisa como outros obtidos em outras pesquisas;

(c) realizar análises exploratórias utilizando técnicas estatísticas:

- análise de correlação de Spearman;

- análise de autocorrelação espacial, utilizando o índice local e global de Moran; e

- análise de clusters de temperatura de superfícies, para identificar padrões do tecido urbano, que produzem a retroalimentação negativa do sistema climático urbano naturalmente, utilizando o sistema de classificação das zonas climáticas locais (ZCLs).

\section{Área de estudos}

A área de estudos compreende uma porção da macrozona urbana (MU) de São José dos Campos (SJC), (2310'46” S; 4553'13" W), São Paulo, Brasil, denominada macrozona de consolidação (MC). A MU de SJC (Figura 2) ocupa cerca de 32,2\% do território municipal, onde residem cerca de $97 \%$ dos 713.943 habitantes (INSTITUTO..., 2019a). É dividida em três macrozonas destinadas ao uso predominantemente urbano: macrozona de consolidação (MC), macrozona de estruturação (ME), macrozona de ocupação controlada (MOC) e duas áreas de proteção ambiental (APAs) (PREFEITURA..., 2019b).

Figura 2 - Localização de São José dos Campos e macrozoneamento urbano

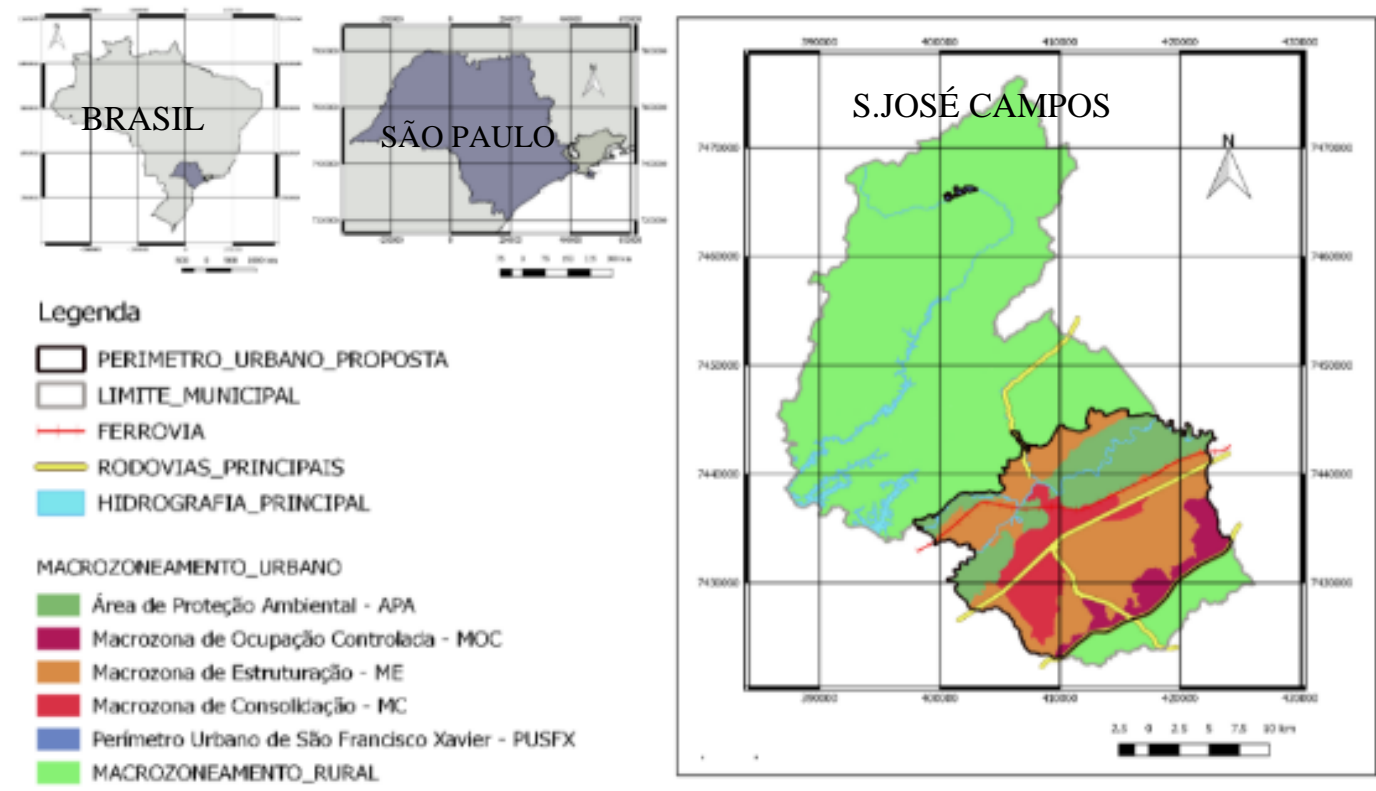

Fonte: adaptado de Instituto Brasileiro de Geografia e Estatística (2019a, 2019b).

242 Ferreira, F. L. e S.; Pereira, E. B.; Labaki, L. C. 
A macrozona de consolidação (MC) foi escolhida, pois é o perímetro onde as atividades urbanas estão plenamente consolidadas, cujo comportamento térmico de sua superfície é fruto das políticas urbanas praticadas no município nos últimos anos, podendo servir de modelo para compreensão do comportamento térmico do tecido urbano consolidado e produção de benchmarking (Figura 3).

O clima em São José dos Campos, dado pela classificação Koppen, é o subtropical úmido (Cfa), com chuvas no verão e seca no inverno. O município está localizado na zona bioclimática 3 (ZB3) (ABNT, 2005). Nos últimos 30 anos a média anual de temperatura do ar (Tar) foi $20,9{ }^{\circ} \mathrm{C}$ e precipitação pluvial foi $1.078,3 \mathrm{~mm}$. Os anos mais frios foram 1989 e 1999 , com Tar média de $19,8{ }^{\circ} \mathrm{C}$ e $19,9{ }^{\circ} \mathrm{C}$ e precipitação pluvial de $1.200,4 \mathrm{~mm}$ e $1.446,1 \mathrm{~mm}$, respectivamente, e os anos mais quentes foram 2015 e 2014, com Tar média de $23,0{ }^{\circ} \mathrm{C}$ e $22,7{ }^{\circ} \mathrm{C}$ e precipitação pluvial de $1.159,2 \mathrm{~mm}$ e $690,3 \mathrm{~mm}$ (Figura 4 ).

\section{Estimativas, mapeamento e integração de dados}

O período de análise foi definido entre 2014 e 2015, anos que apresentaram as maiores médias anuais de temperatura do ar (Tar) nos últimos 30 anos. As estimativas foram realizadas utilizando-se os produtos da coleção nível-2 do satélite Landsat-8 (L8-L2) para a órbita 219, ponto 76, com incidência de nuvens abaixo de $5 \%$, adquiridas às 13 h00 UTC ou 10 horas em horário local. A coleção level-2 derivada da level-1 contempla as correções atmosféricas relativas aos fatores geofísicos, que influenciam os dados coletados pelos sensores a bordo dos satélites, como os gases presentes na atmosfera, aerossóis e altitude. As estimativas e o mapeamento das características espectrais e da temperatura das superfícies foram feitas utilizando-se a calculadora raster do software QGis.

A primeira etapa de estimativa dos dados consistiu na adequação da projeção cartográfica das imagens ao Sistema de Referência Geocêntrico das Américas (SIRGAS2000) (IBGE, 2019b). A segunda, no ajuste do fator de escala das imagens (FE), procedimento realizado para padronizar as unidades dos dados. Esse procedimento foi realizado na calculadora raster do QGis, onde os valores de cada pixel da imagem são multiplicados pelos FE. O FE é estabelecido por produto da coleção L8-L2 (VERMOTE et al., 2016; ZANTER, 2019). Os produtos da coleção L8-L2 utilizados nesta pesquisa foram: o índice de vegetação por diferença normalizada (NDVI), o índice de umidade por diferença normalizada (NDMI), bandas 2, 3, 4, 5, 6 e 7 de refletância no topo da atmosfera, cujo fator de escala indicado para adequação das unidades é 0,0001 , e banda 10, que corresponde à temperatura de brilho no topo da atmosfera (TB) cujo fator de escala a ser aplicado é 0,1 .

\section{Figura 3 - Macrozona de consolidação de SJC}

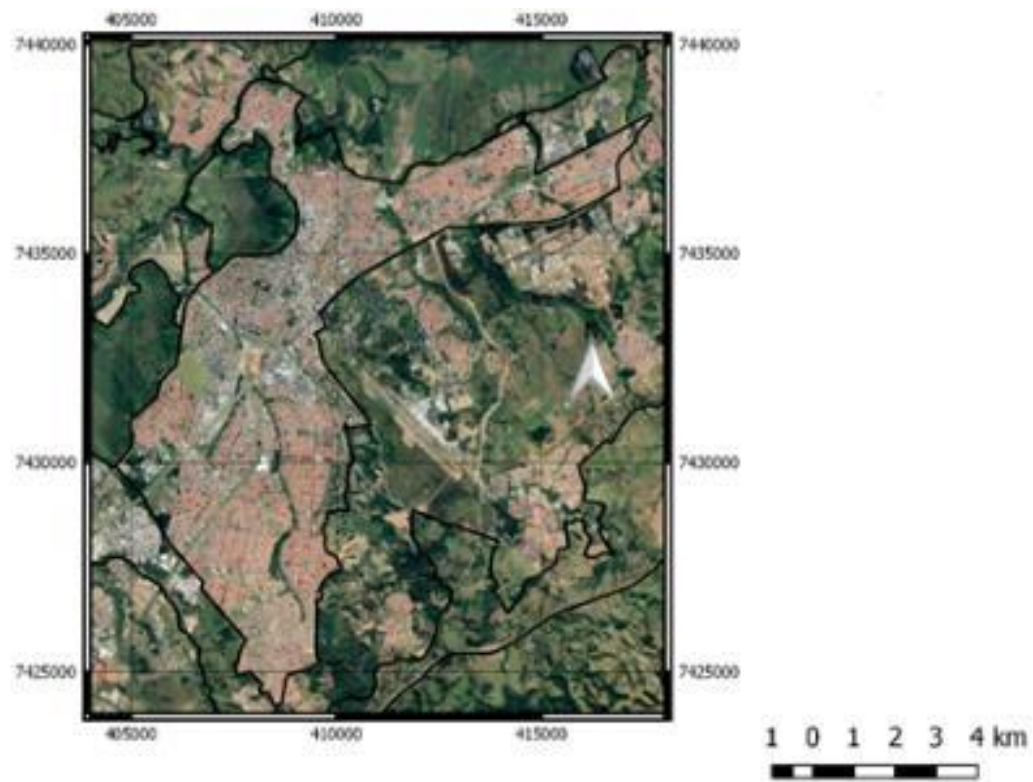

Fonte: adaptado de Google Earth (2019). 
Figura 4 - Evolução da Tar e preciptação pluvial em SJC

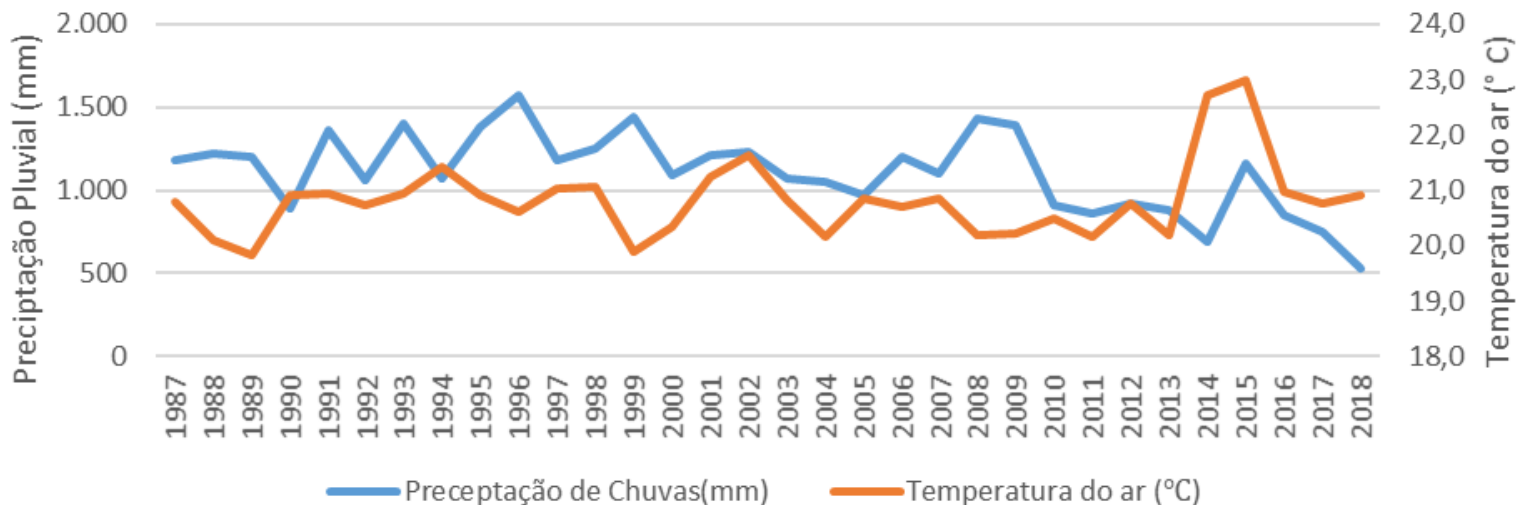

Fonte: adaptado de Redemet (2018).

Tabela 1 - Data de aquisição das imagens, temperatura da superfície e temperatura do ar

\begin{tabular}{c|c|c|c|c}
\hline \multirow{2}{*}{ Data } & \multicolumn{2}{|c|}{ CETESB_SJC } & \multicolumn{2}{c}{ AEROPORTO_SJC } \\
\cline { 2 - 5 } & TS $\left({ }^{\circ} \mathbf{C}\right)$ & Tar $\left({ }^{\circ} \mathbf{C}\right)$ & TS $\left({ }^{\circ} \mathbf{C}\right)$ & Tar $\left({ }^{\circ} \mathbf{C}\right)$ \\
\hline $08 / 02 / 2014$ & 35,4 & 28,9 & 38,6 & 32,0 \\
$28 / 03 / 2014$ & 35,2 & 24,3 & 36,4 & 24,0 \\
$15 / 05 / 2014$ & 23,2 & 20,1 & 25,5 & 21,0 \\
$02 / 07 / 2014$ & 21,1 & 18,1 & 22,9 & 19,0 \\
$03 / 08 / 2014$ & 25,8 & 21,2 & 29,3 & 24,0 \\
$06 / 10 / 2014$ & 28,8 & 18,5 & 31,0 & 21,0 \\
$26 / 12 / 2014$ & 27,8 & 24,8 & 31,5 & 29,0 \\
$10 / 01 / 2015$ & 33,2 & 27,6 & 35,3 & 32,0 \\
$21 / 01 / 2019$ & 28,8 & 24,7 & 32,0 & 28,0 \\
\hline Mediana & 4,5 & 24,3 & 31,5 & 24,0 \\
\hline Média & 28,8 & 23,1 & 31,4 & 25,6 \\
\hline Desvio padrão & 5,1 & 3,9 & 5,1 & 4,9 \\
\hline
\end{tabular}

A terceira etapa consistiu em estimar as variáveis. A fração de cobertura de vegetação (FCV) foi estimada a partir do NDVI (CARLSON; RIPLEY, 1997), utilizando-se o produto da coleção L8-L2. Os parâmetros utilizados para o cálculo do FCV (Equação 1) foram obtidos no mapa de percentual de NDVI gerado pelo software GeoDa, para cada imagem analisada. Os valores de NDVI mínimo ou NDVI do solo (NDVIS) e NDVI máximo ou NDVI da vegetação $\left(\mathrm{NDVI}_{\mathrm{VEG}}\right)$ foram definidos considerando-se o menor e o maior valor positivo de NDVI encontrado na cena.

$F C V=\left(\frac{N D V I-N D V I_{S}}{N D V I_{V E G}-N D V I_{S}}\right)^{2}$

Eq. 1

Onde:

FCV: fração de cobertura de vegetação;

NDVI: índice da diferença normalizada de vegetação;

NDVIs: índice da diferença normalizada do solo exposto; e

NDVI $_{V E G}$ : índice da diferença normalizada de solo com cobertura vegetal.

A emissividade da superfície $(\mathcal{E})$ foi estimada a partir do NDVI, utilizando-se o método dos limites, ou "NDVI Threshold method", baseado na razão entre vegetação e solo exposto (SOBRINO; RAISSOUNI, 2000). Nesse método a emissividade inferida a cada pixel é obtida a partir do NDVI em cada pixel. Para os pixels com água ou NDVI $<0$ é inferida $\varepsilon=0,991$; para pixels com predominância de vegetação ou NDVI $>0,5, \varepsilon=0,984$; para pixels com predominância de solo exposto, sem vegetação ou NDVI entre 0 e 0,2 , $\varepsilon=0,964$. Nos pixels heterogêneos, cujos valores de NDVI ocorrem entre 0,2 e $0,5(0,2<=$ NDVI $<=0,5)$ a $\varepsilon$ é aferida a partir da Equação 2 (JIN et al., 2015; SOBRINO et al., 2008; SOBRINO; RAISSOUNI, 2000).

$\varepsilon m i x=\varepsilon v * F C V+\varepsilon s *(1-F C V)+C s$

Eq. 2

244 Ferreira, F. L. e S.; Pereira, E. B.; Labaki, L. C. 
Onde:

Emix: emissividade para pixels mistos ou heterogêneos;

Es: emissividade do solo (0,964);

Ev: emissividade da vegetação $(0,984)$;

FCV: fração de cobertura de vegetação; e

Cs: efeito de cavidade.

O efeito da cavidade da superfície (Cs) é utilizado para representar a rugosidade de superfícies heterogêneas, onde a geometria das superfícies é representada pelo fator geométrico (F) (Equação 3) (SOBRINO; CASELLES; BECKER, 1990). O fator geométrico (F) utilizado no cálculo do efeito de cavidade pode variar de 0 a 1 . Em uma superfície totalmente plana o fator geométrico é 0 . Em superfícies mistas e não uniformes considera-se $\mathrm{F}=0,55$ (SOBRINO; RAISSOUNI, 2000).

$C s=(1-\varepsilon s) * \varepsilon v * F *(1-F V C)$

Onde:

Cs: efeito de cavidade;

Es: emissividade do solo (0,964);

Ev: emissividade da vegetação $(0,984)$;

F: fator geométrico $(0,55)$; e

FCV: fração de cobertura de vegetação.

O albedo das superfícies (A) foi estimado a partir dos produtos de refletância no topo da atmosfera utilizando-se o algoritmo Surface Energy Balance Algorithm (SEBAL), onde o A é calculado em duas etapas. Na primeira estima-se o albedo no topo da atmosfera (Atoa) a partir da utilização de coeficientes de ponderação (Tabela 2) aplicados em cada banda de refletância do L8 (Equação 4) (WATERS et al., 2002) (TASUMI; ALLEN; TREZZA, 2008).

$A_{T O A}=\sum_{b=1}^{7}\left[A_{s, b} * W_{b}\right]$

Eq. 4

Onde:

$\mathrm{A}_{\mathrm{TOA}}$ : albedo integrado no topo da atmosfera $(0.3-4,0 \mu \mathrm{m})$;

b: banda de refletância; e

$\mathrm{W}_{\mathrm{b}}$ : coeficiente de ponderação.

$\mathrm{Na}$ segunda etapa incorporam-se as correções relativas à refletância e transmissividade do ar para obter o albedo das superfícies (A) (Equação 5 e Equação 6).

$A=\frac{A_{T O A}-A_{A T M}}{T s w^{2}}$

Eq. 5

$\mathrm{T} s w=0,75+2 \times 10^{-5} \times Z$

Eq. 6

Onde:

A: albedo na superfície;

$\mathrm{A}_{\text {TOA: }}$ albedo no topo da atmosfera;

$\mathrm{A}_{\mathrm{ATM}}$ albedo atmosférico $(0,03)$

$\mathrm{T}_{\mathrm{sw}}$ : transmissividade da radiação solar no ar; e

Z: elevação acima do nível do mar (600 m em SJC).

Tabela 2 - Coeficientes de ponderação (Wb) utilizados para estimar A TOA $_{\text {TO }}$

Coeficientes de nonderacão (Wb)

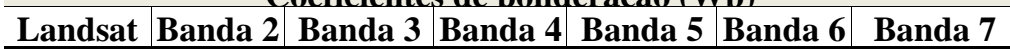

\begin{tabular}{|l|l|l|l|l|l|l|}
\hline $\mathrm{W}_{\mathrm{b}}$ & 0,293 & 0,274 & 0,233 & 0,157 & 0,033 & 0,036 \\
\hline
\end{tabular}

Fonte: Walters et al. (2002). 
A TS foi estimada a partir da imagem de $\mathcal{E}$ gerada na etapa anterior e do produto de temperatura de brilho ou temperatura radiante (TB) da coleção L8-L2, utilizando-se a Equação 7, que considera os efeitos da emissividade na TS (ARTIS; CARNAHAN, 1982).

$T S_{=} \frac{T B}{1+\left(\frac{\lambda T B}{\rho}\right) \ln \varepsilon} \mathrm{TS}=\frac{\mathrm{TB}}{1+\left(\frac{\lambda^{*} \mathrm{~TB}}{\rho}\right) * \operatorname{Ln} \varepsilon}-273,16$

Onde:

TS: temperatura da superfície $\left({ }^{\circ} \mathrm{C}\right)$;

TB: temperatura de brilho $(\mathrm{K})$;

$\lambda$ : comprimento médio de onda emitido no intervalo da banda 10 do L8 (10,895 $\mu \mathrm{m})$;

p: $1,438 * 10^{-2} \mathrm{~m} \mathrm{~K}$;

Ln: logaritmo natural; e

$\varepsilon$ : emissividade da superfície.

O mapeamento e a integração dos dados foram feitos a partir da criação do espaço celular ou grade regular onde o polígono delimitado pela macrozona de consolidação (MC) foi discretizado em 15.192 células, com dimensão de $60 \mathrm{~m}$ x $60 \mathrm{~m}$ ou $3.600 \mathrm{~m}^{2}$. Esse procedimento gera um arquivo shapephile (shp) com uma tabela de atributos vinculada, na qual as características espectrais e temperatura das superfícies obtidas pela análise das nove imagens do satélite Landsat8 são armazenadas. O preenchimento da tabela de atributos, bem como a criação do espaço celular, foi feito no "FillCell", gerenciador de scripts de preenchimento de células compatível com o LuccME e INPE-EM 3.X versão 2.0 (INSTITUTO..., 2018). O preenchimento das células foi feito utilizando-se o operador "average", que calcula o valor do atributo a partir da média dos valores dos pixels dentro da área de cada célula. A temperatura da superfície (TS), bem como os valores utilizados para representar as variáveis espectrais, definem-se como a média dos valores dos pixels, lidos pelo satélite, que se encontram dentro da célula definida na discretização do espaço.

\section{Análises exploratórias}

As análises exploratórias consistem em métodos que tem como base os princípios da estatística descritiva, e são utilizadas para identificar padrões, associações ou interdependências entre as variáveis de conjuntos de dados, bem como identificar padrões de ocorrência, tendências ou resultados extremos.

Nesta pesquisa, as análises exploratórias foram realizadas em 3 etapas, com o objetivo de resumir as informações contidas nas 15.192 células, que compõem o conjunto de dados utilizado para representar a macrozona de consolidação urbana (MC) de São José dos Campos, avaliar a interdependência entre as variáveis espectrais e a temperatura das superfícies, bem como as relações espaciais definidas pela distribuição da temperatura das superfícies.

A primeira etapa consistiu em verificar a correlação entre TS, definida como variável dependente (Y), e albedo (A), emissividade (E), fração de cobertura de vegetação (FCV) e NDMI, definidas como variáveis explicativas $(\mathrm{X})$. Os valores de correlação foram calculados utilizando-se o coeficiente de correlação de Spearman $\left(\rho_{\mathrm{s}}\right)$, utilizado para dados não paramétricos (MARÔCO, 2007).

A segunda etapa foi realizada para verificar a dependência espacial de TS, em um mesmo ano e entre diferentes estações do ano. A representação computacional de dependência espacial é denominada autocorrelação espacial, derivada do conceito estatístico de correlação. Sua aferição é feita utilizando-se indicadores globais ou locais, nos quais a dependência espacial é estabelecida considerando-se os valores do atributo em uma região e os valores desse mesmo atributo nas regiões vizinhas. Os indicadores globais consistem em um valor único, calculado para representar a associação espacial de um conjunto de dados em uma extensão de área, enquanto os indicadores locais (derivados dos globais) indicam as associações locais, que ocorrem dentro de uma área maior, e expressam as relações pontuais e localizadas (DRUCK et al., 2004). Ambos são estabelecidos considerando-se os valores dos vizinhos mais próximos e definidos a partir da matriz de vizinhança ou contiguidade. O conceito de matriz de vizinhança ou contiguidade (W) é estabelecido pela proximidade espacial e variabilidade dos dados entre vizinhos, sendo considerada elemento essencial para se estabelecer as relações espaciais (ANSELIN, 2005).

Nas análises de autocorrelação espacial os testes de significância estatística devem ser aplicados para testar a significância dos índices de autocorrelação espacial medidos, que devem corresponder a um "extremo" da distribuição simulada, para que seja descartada a hipótese nula de independência espacial. Em amostras não 
paramétricas utiliza-se o teste de pseudosignificância ou permutação para verificar se os resultados não ocorrem por acaso. Nesse teste, simulações computacionais são realizadas, diferentes arranjos espaciais são testados e uma distribuição empírica é gerada (ANSELIN, 2010; DRUCK et al., 2004).

Nesta pesquisa, a dependência espacial foi estimada a partir do índice global de Moran (I), através da função "univariate", do software GeoDa, para aferir a dependência espacial da TS no espaço em uma mesma data e a "bivariate" para aferir a dependência espacial de TS no espaço em datas diferentes. A matriz de vizinhança ou contiguidade adotada foi a denominada "rainha" de ordem 1. A matriz de vizinhança estabelecida pelo critério da "rainha" determina como unidades vizinhas, aquelas que têm algum ponto comum, seja na lateral ou diagonal (ANSELIN, 2005).

A terceira etapa teve como meta agrupar áreas com padrões homogêneos de TS e identificar as ZCLs associadas, bem como suas características espectrais. A técnica utilizada foi a análise de cluster, onde áreas homogêneas são agrupadas em função de medidas de semelhança ou dissemelhança (MARÔCO, 2007). O procedimento foi realizado no GeoDa, no qual os dados de TS, obtidos para as imagens de 2014 e 2015 , consolidados no espaço celular, foram utilizados para o mapeamento de clusters. O algoritmo utilizado foi o "K-Medians" e a função de distância a Euclidiana (GEODA, 2019). O número de clusters a reter foi definido com base nas medidas de dissemelhança entre clusters e nas medidas de semelhança dentro dos clusters (MARÔCO, 2007).

\section{Resultados e discussão}

\section{Características espectrais e temperatura de superfície integradas no espaço celular}

Os resultados da integração das informações são apresentados separadamente para cada variável: FCV, E, A, NDMI e TS. Os resultados são ilustrados pelos mapas gerados para a imagem de 10/01/2015, para cada variável. Em paralelo aos mapas, são apresentados os resultados obtidos para cada imagem analisada, em forma de gráfico de caixa ou "boxplots", que resumem as informações obtidas para as 15.192 células, e uma tabela com a síntese dos resultados (Figuras 5 a 9). Os gráficos de caixa ou "boxplots" contêm seis informações elementares de conjuntos de dados: mínimo, primeiro quartil, mediana, terceiro quartil e valores máximos e o valor médio (UPTON; COOK, 1996).

Os resultados acima refletem a influência da variação climática sazonal sobre as variáveis em estudo, bem como as condições meteorológicas no período analisado. A TS mediana obtida para a MC, compilando-se o resultado de todas as imagens, foi de $28,9{ }^{\circ} \mathrm{C}$, a menor foi obtida em $02 / 07 / 2014\left(21{ }^{\circ} \mathrm{C}\right)$, com Tar de $18{ }^{\circ} \mathrm{C}$, e a maior em 08/02/2014 $\left(35,8{ }^{\circ} \mathrm{C}\right)$, com Tar de $32{ }^{\circ} \mathrm{C}$. Os resultados do mapeamento da FCV, NDMI e emissividade refletem a escassez de chuvas em fevereiro, julho, agosto e outubro de 2014, que foi um dos anos mais secos dos últimos 30 anos. Os resultados de albedo, por sua vez, espelham a heterogeneidade do tecido urbano.

\section{Verificação dos resultados}

A verificação dos resultados das características espectrais, estimados nesta pesquisa por sensores remotos, foi feita no sentido de avaliar sua adequabilidade, comparando-se os resultados estimados para cada variável aferida na área de estudos com os resultados obtidos em outras pesquisas, que são utilizados como parâmetros, na modelagem do clima urbano.

O processo de verificação por comparação foi feito a partir da criação de 5 novos conjuntos de dados. Os novos conjuntos foram criados para representar os tipos de cobertura do solo encontrados na MC: vegetação densa, grama ou pasto, água, solo exposto e área construída ou urbanizada (Figura 10). Para cada um dos cinco novos conjuntos, a mediana foi calculada, e utilizada como referência, para comparação com outras bases de dados (Tabela 3). 
Figura 5 - Conjunto de dados de FCV

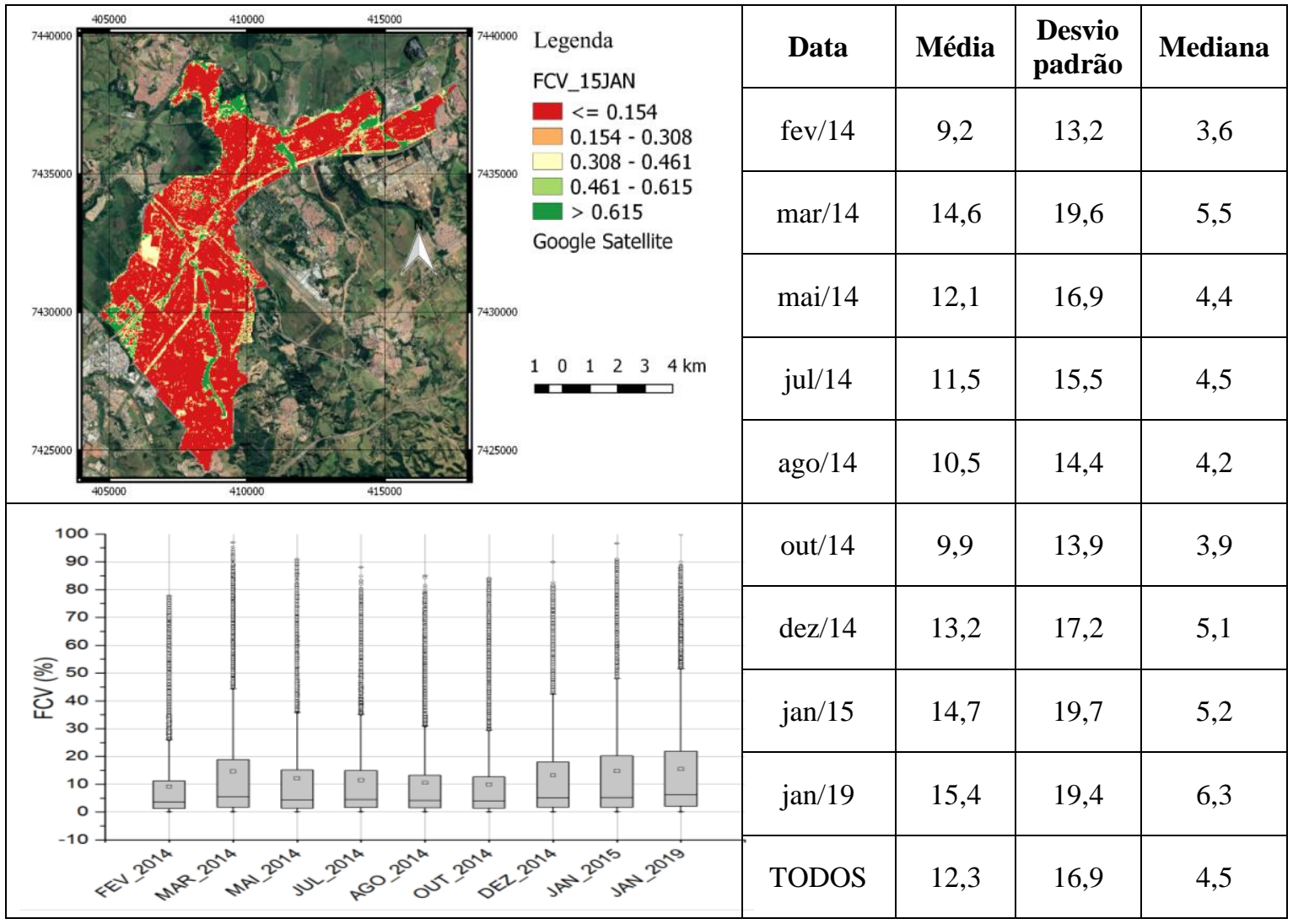

Figura 6 - Conjunto de dados de emissividade

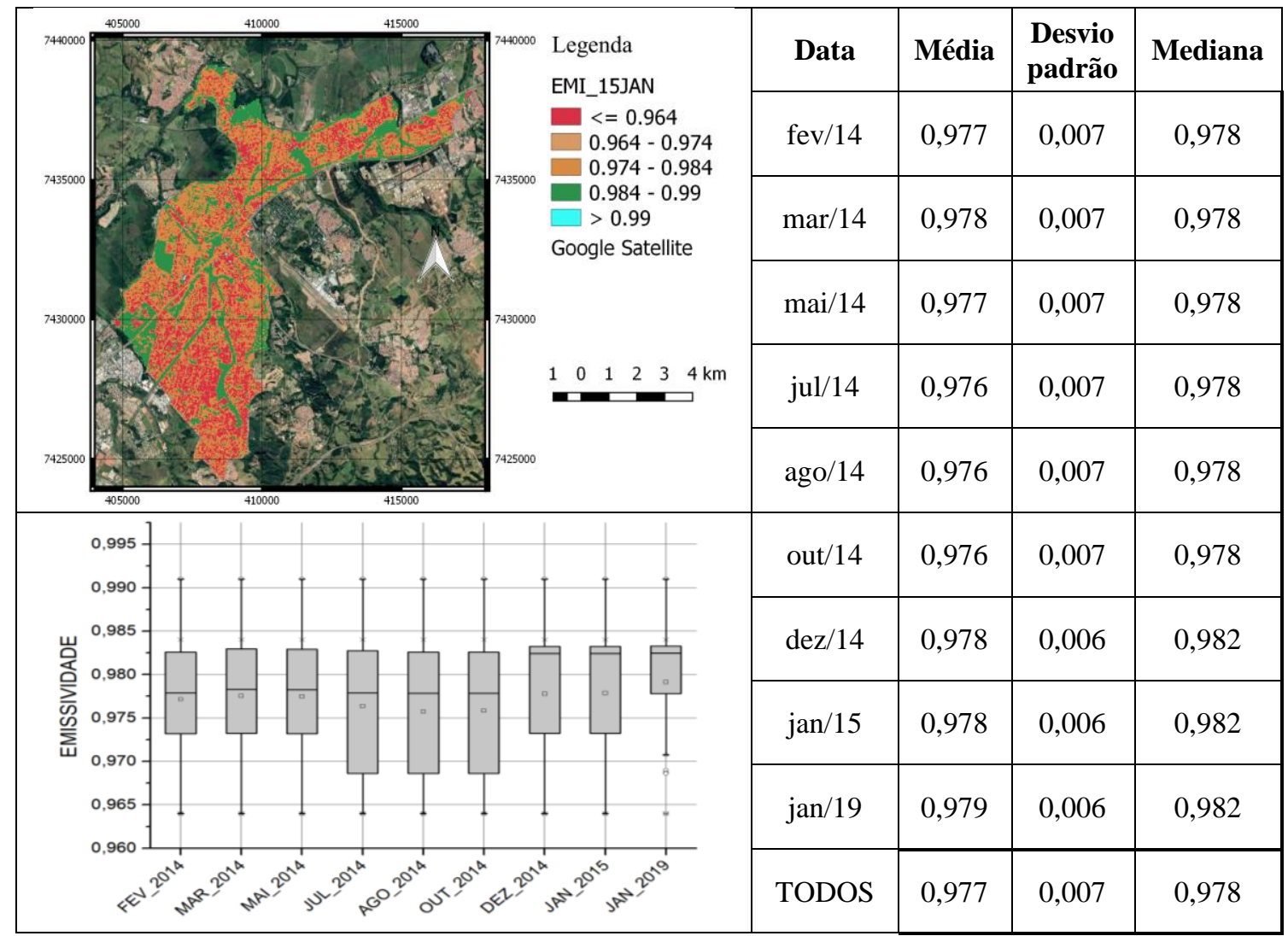

248 Ferreira, F. L. e S.; Pereira, E. B.; Labaki, L. C. 
Figura 7 - Conjunto de dados de albedo

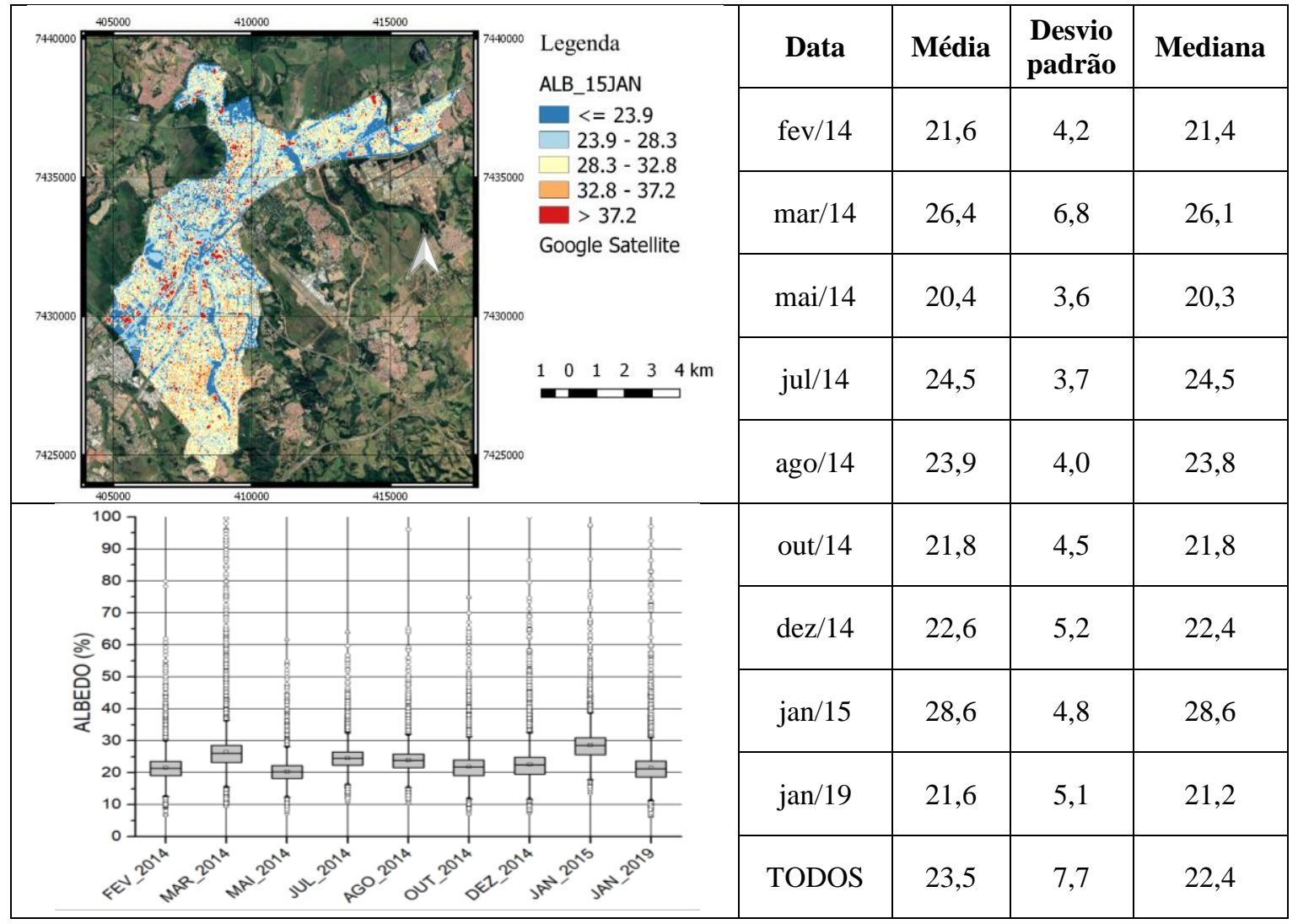

Figura 8 - Conjunto de dados de NDMI

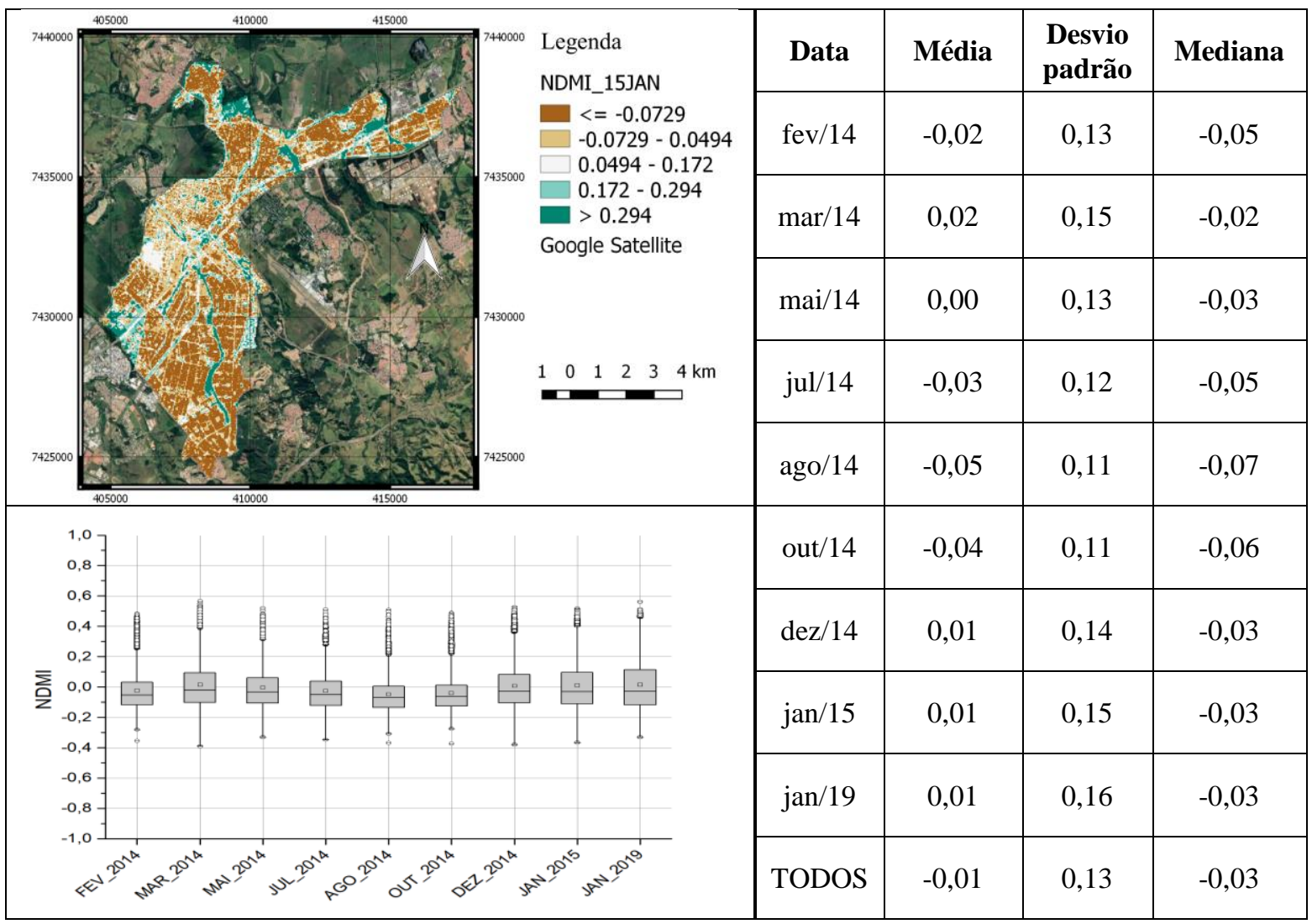


Figura 9 - Conjunto de dados de TS

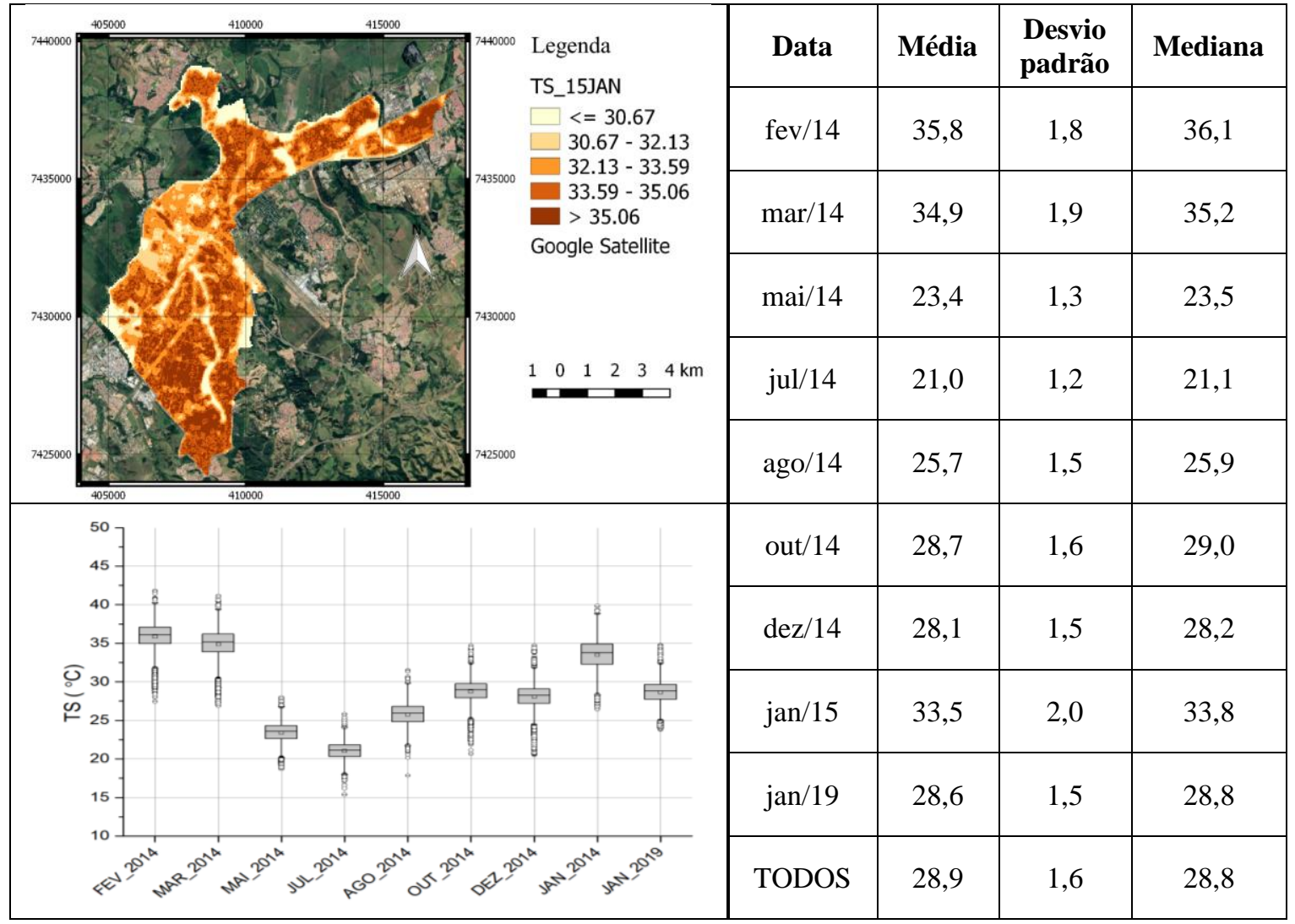

Figura 10 - Amostras selecionadas

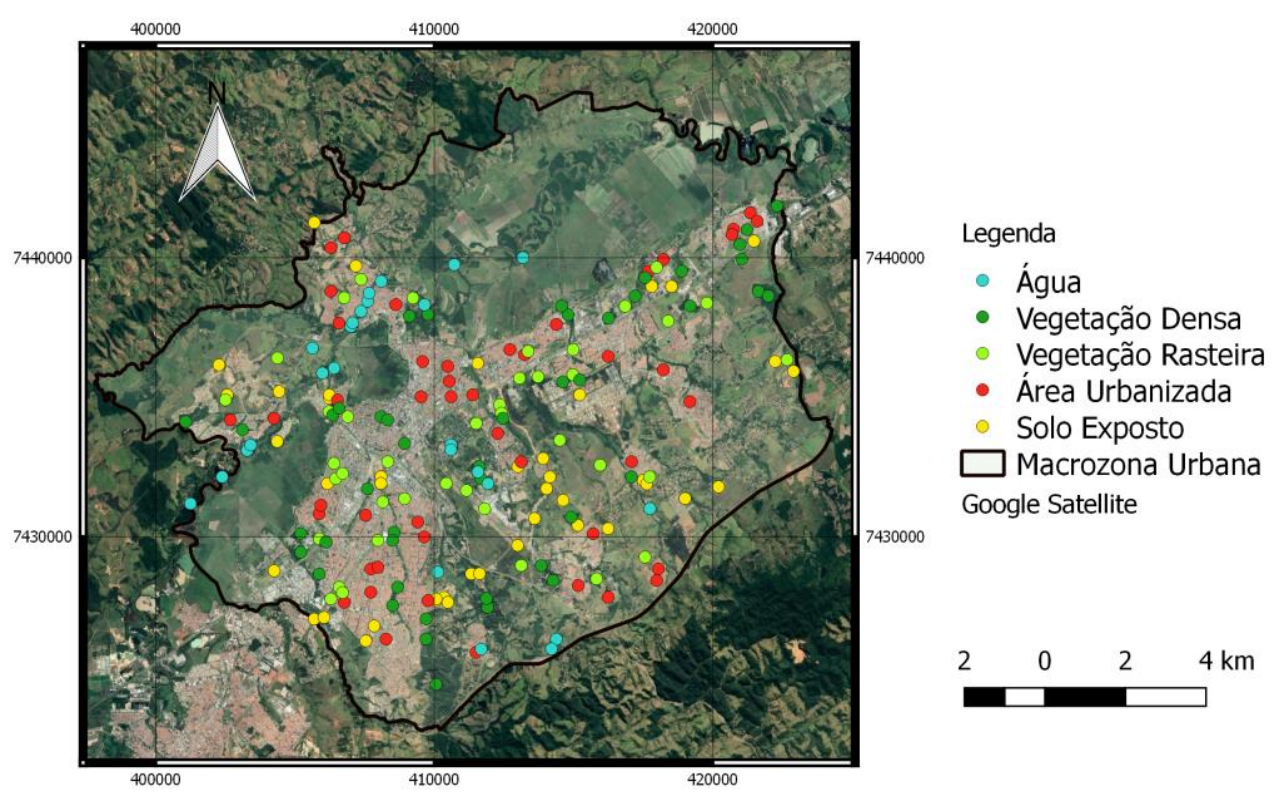


Tabela 3 - Valores estimados nesta pesquisa e valores obtidos em outras fontes

\begin{tabular}{c|c|c|c|c|c|c}
\hline & FCV (\%) & NDMI & \multicolumn{2}{|c|}{ ALBEDO } & \multicolumn{2}{c}{ EMISSIVIDADE } \\
\hline $\begin{array}{c}\text { COBERTURA } \\
\text { DO SOLO }\end{array}$ & Estimado & Estimado & Estimado & $\begin{array}{c}\text { Stewart e Oke } \\
\mathbf{( 2 0 1 2 )}\end{array}$ & Estimado & $\begin{array}{c}\text { Jin } \text { et al. } \\
(\mathbf{2 0 1 5})\end{array}$ \\
\hline Área urbana & 1,06 & $-0,16$ & 0,24 & 0,10 a 0,35 & 0,973 & 0,964 \\
\hline Solo exposto & 3,09 & $-0,03$ & 0,22 & 0,20 a 0,35 & 0,982 & 0,964 \\
\hline Grama e pasto & 45,62 & 0,22 & 0,18 & 0,15 a 0,30 & 0,984 & 0,984 \\
\hline Água & 16,25 & 0,43 & 0,09 & 0,02 a 0,10 & 0,989 & 0,991 \\
\hline Floresta & 78,17 & 0,42 & 0,13 & 0,10 a 0,20 & 0,984 & 0,984 \\
\hline
\end{tabular}

Os valores de FCV obtidos para vegetação densa (78,14\%), grama ou pasto $(45,62 \%)$, áreas construídas $(1,06 \%)$ e solo exposto $(3,09 \%)$ são compatíveis com o esperado para o tipo de cobertura em análise. Os valores de FCV (16,25\%), obtidos para amostras de água, indicam a presença de matéria orgânica, típica de áreas naturalmente alagadas, como rios e lagos.

Os valores positivos de NDMI, obtidos para vegetação densa $(0,451)$, grama ou pasto $(0,227)$ e água $(0,433)$, configuram a presença de água ou umidade na superfície. Os valores negativos, obtidos para solo exposto ou áreas em processo de urbanização $(-0,036)$ e áreas construídas, $(-0,161)$ indicam ausência.

Os valores de emissividade e albedo, obtidos para os tipos de cobertura avaliados, com exceção da categoria solo exposto, são compatíveis com os obtidos em pesquisas anteriores (JIN et al., 2015; STEWART; OKE, 2012; WATERS et al., 2002). A emissividade do solo exposto $(0,982)$ na área de estudo, superior ao obtido em outras pesquisas $(0,964)$ (JIN et al., 2015), reflete as características do solo na área de estudos: o latossolo vermelho amarelo (LVA), típico de regiões tropicais, que é caracterizado por diferentes níveis de óxido de ferro e matéria orgânica (FERNANDES et al., 2004).

A verificação dos valores obtidos para a TS foi feita a partir da comparação entre os valores de Tar, medidos nas estações meteorológicas (Cetesb e aeroporto), e os valores de TS estimados para o pixel onde a estação está locada. Os resultados do coeficiente de determinação $\left(\mathrm{R}^{2}\right)$ apontam que aproximadamente $60 \%$ da variabilidade da TS está relacionada à variação da Tar (Figura 11). Vale a pena lembrar que a variação da TS, embora influenciada pela Tar, também está relacionada às características espectrais da superfícies e condições climáticas, que influenciam os fluxos de calor e determinam o balanço de energia nas superfícies.

\section{Análises exploratórias}

Os coeficientes de correlação de Spearman $\left(\rho_{\mathrm{s}}\right)$ médios obtidos entre TS e $\varepsilon$, FCV e NDMI, para todas as datas analisadas, foram $-0,764,-0,779$ e $-0,730$, respectivamente, indicando que quanto maior TS, menor a $\varepsilon$, FCV e NDMI. O $\rho_{\mathrm{s}}$ entre TS e A foi de 0,57 , apontando uma fraca correlação positiva. Os valores negativos obtidos entre TS, $\varepsilon$, FCV e NDMI refletem a capacidade de resfriamento de áreas com maior conteúdo de água e vegetação. Os valores de correlação obtidos entre TS e A necessitam de uma avaliação mais detalhada, pois são afetados pelos elementos constituintes de superfícies heterogêneas: água, vegetação ou construções, que possuem diferentes meios de processar a radiação solar incidente e o ganho de calor. As áreas verdes, por exemplo, descritas anteriormente como infraestrutura verde, têm alta capacidade de processar o calor e manter-se mais frias que as áreas construídas sob as mesmas condições climáticas.

As áreas verdes têm baixo albedo, pois absorvem radiação solar visível no processo de fotossíntese, com alta capacidade de processar o calor, enquanto as áreas construídas possuem albedo superior ao de áreas verdes, porém baixa capacidade de processar o calor, o que induz a TS superiores. Esse fato causa uma perturbação nos resultados de correlação entre TS e A em superfícies heterogêneas, como o tecido urbano.

Os resultados das análises de autocorrelação espacial para uma mesma data indicam a alta dependência espacial de TS, com valores acima de 0,80. Já as análises voltadas para aferir a dependência espacial de TS em diferentes datas mostraram índices menos expressivos, mas que indicam a dependência espacial de TS, apesar da variabilidade climática sazonal e das mudanças inerentes à dinâmica urbana. O índice de Moran (I) obtido para análises realizadas entre inverno e verão (julho/2014 e janeiro/2015) foi de 0,655; o índice obtido entre imagens de uma mesma estação (janeiro/2014 e janeiro/2015) foi de 0,788; e para uma mesma data (janeiro/2015) foi de 0,87. Esses resultados podem ser observados nos gráficos de espalhamento de Moran, mapas de clusters, e mapas de significância obtidos para cada situação analisada (Figuras 12a, 12b, e 12 c). Na legenda dos mapas apresentados o número entre parênteses indica o número de células classificadas de acordo com o índice de autocorrelação espacial e índice de significância. 
Figura 11 - Comparação da TS $\left({ }^{\circ} \mathrm{C}\right)$ estimada no pixel e $\operatorname{Tar}\left({ }^{\circ} \mathrm{C}\right)$ nas estações meteorológicas

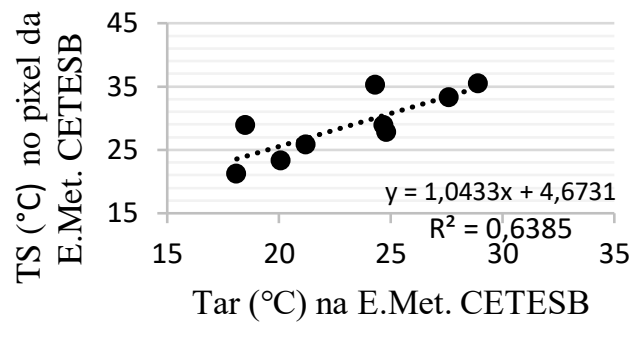

- $\quad \mathrm{TS}\left({ }^{\circ} \mathrm{C}\right) \quad \cdots . . . .$. Linear $\left(\mathrm{TS}\left({ }^{\circ} \mathrm{C}\right)\right)$

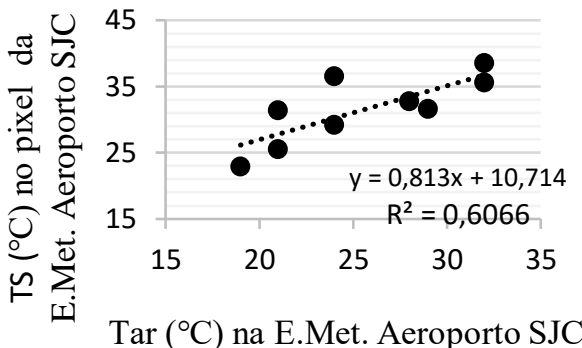

- TS $\left({ }^{\circ} \mathrm{C}\right) \cdots \cdots \cdot$..... Linear $\left(\mathrm{TS}\left({ }^{\circ} \mathrm{C}\right)\right)$

Figura 12 - Gráfico de espalhamento de Moran, mapa de cluster de autocorrelação espacial e mapa de significância de TS em diferentes situações
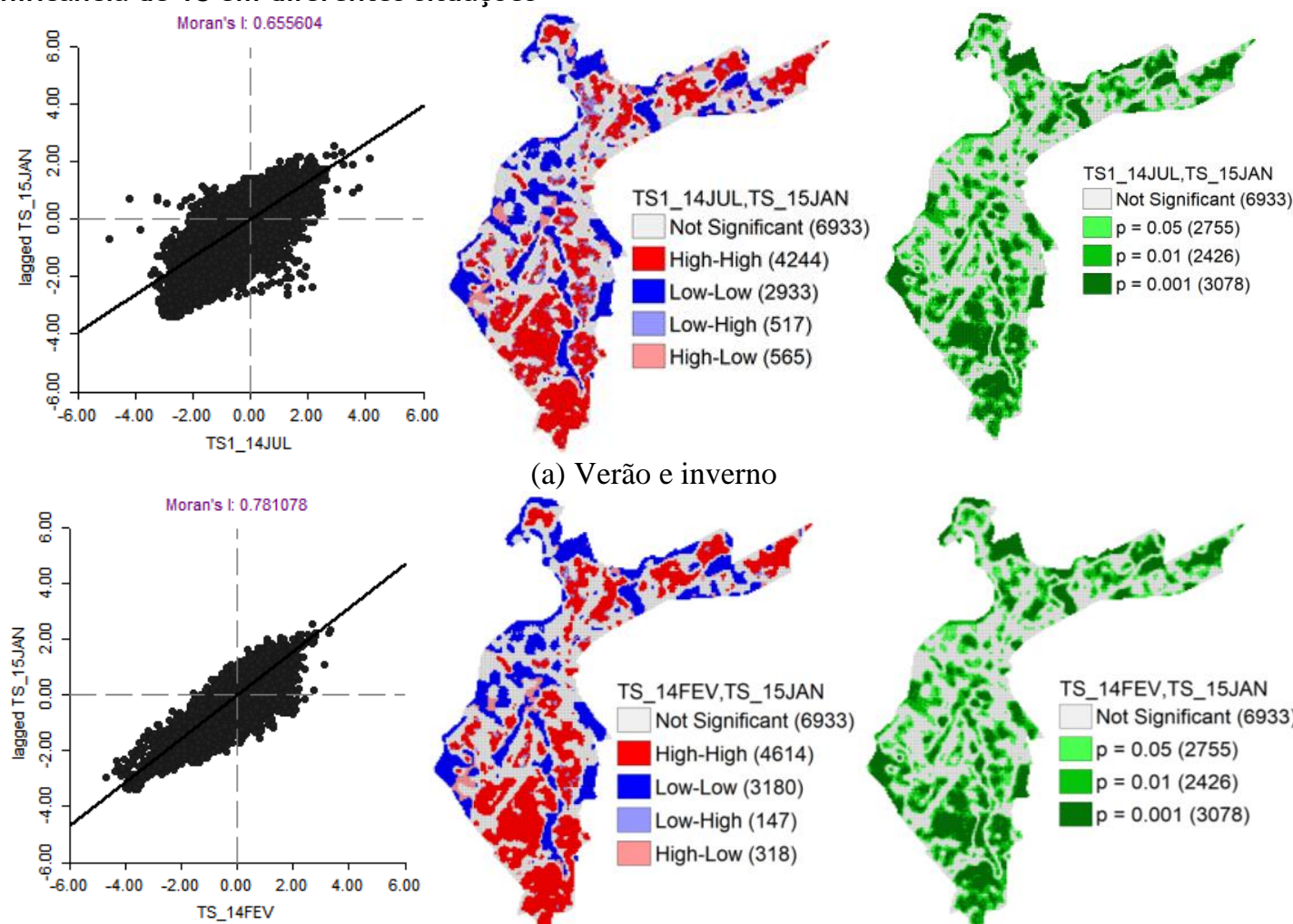

(a) Verão e inverno
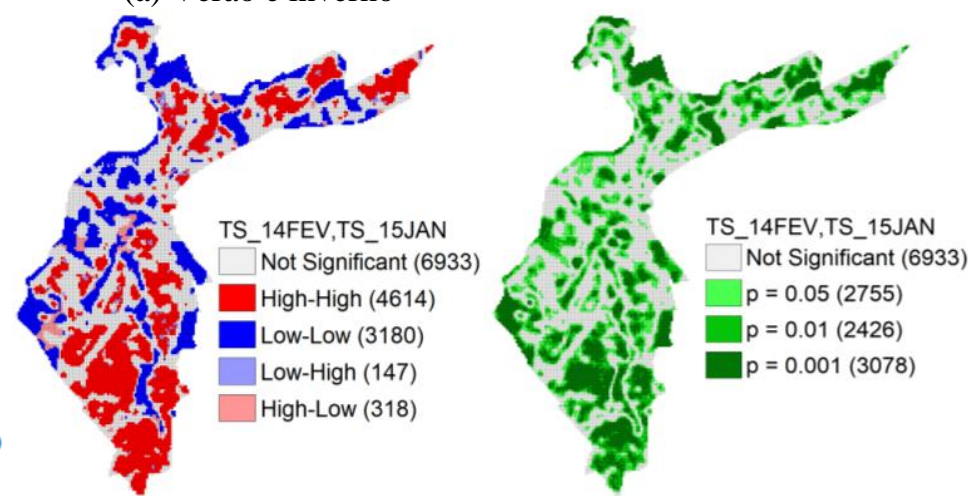

(b) Verão e verão
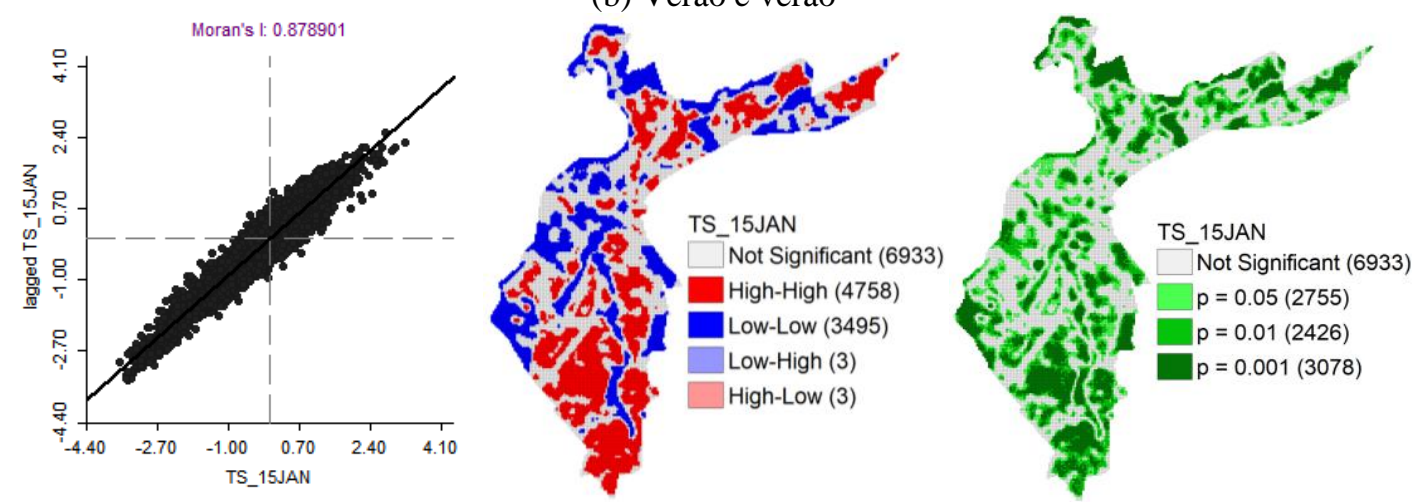

(c) Verão

252 Ferreira, F. L. e S.; Pereira, E. B.; Labaki, L. C. 
As análises de cluster iniciaram-se com a definição do número de clusters a reter. A definição foi feita a partir dos resultados de testes realizados no GeoDa, em agrupamentos de 5 a 10 clusters. Os valores referenciais, para decisão do número de clusters a reter, foram feitos com base nas medidas de dissemelhança entre clusters e nas medidas de semelhança dentro dos clusters, visto que os resultados dos testes apontam que o coeficiente de determinação $\left(\mathrm{R}^{2}\right)$ é superior a $80 \%$, em todos os números de agrupamentos testados (Figura 13a). Os resultados obtidos nos testes (Figura 13b) indicam que somente a partir de 9 clusters a soma dos quadrados entre clusters é relativamente superior à soma dos quadrados dentro dos clusters. A soma dos quadrados entre clusters aponta a variabilidade ou dissemelhança entre grupos, devendo ser a maior possível, enquanto a soma dos quadrados dentro dos clusters aponta a variabilidade interna de seus componentes, e deve ser a menor possível (GEODA, 2019; MARÔCO, 2007).

Nesse sentido, foram criados 9 clusters (CL1, CL2, CL3, CL4, CL5, CL6, CL7, CL8 e CL9), gerados a partir da distribuição de TS, utilizando-se o software GeoDa (Figura 14). Na sequência os dados foram exportados para o software QGis, no qual foram separados em 9 novos conjuntos para extração de suas características espectrais (Figuras 13 a 19).

Figura 13 - Testes para definição do numero de clusters

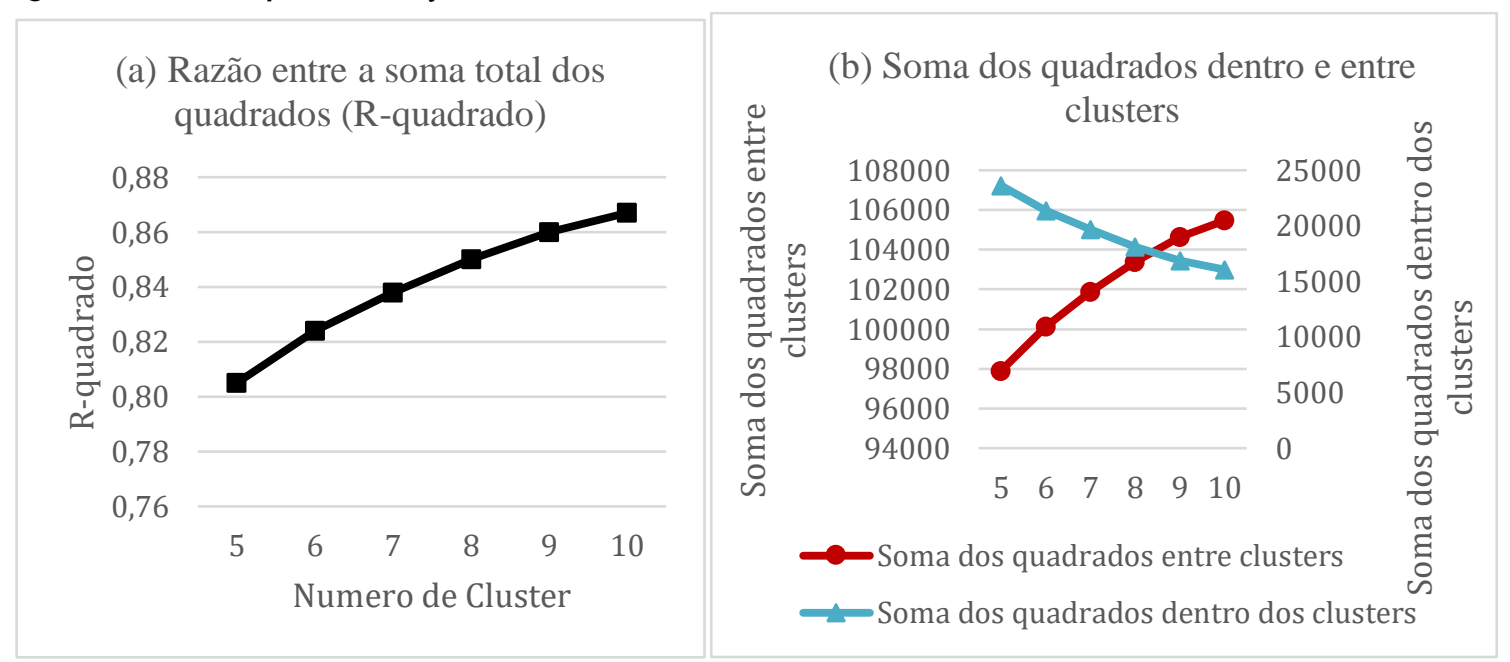

Figura 14 - Mapa de clusters de TS

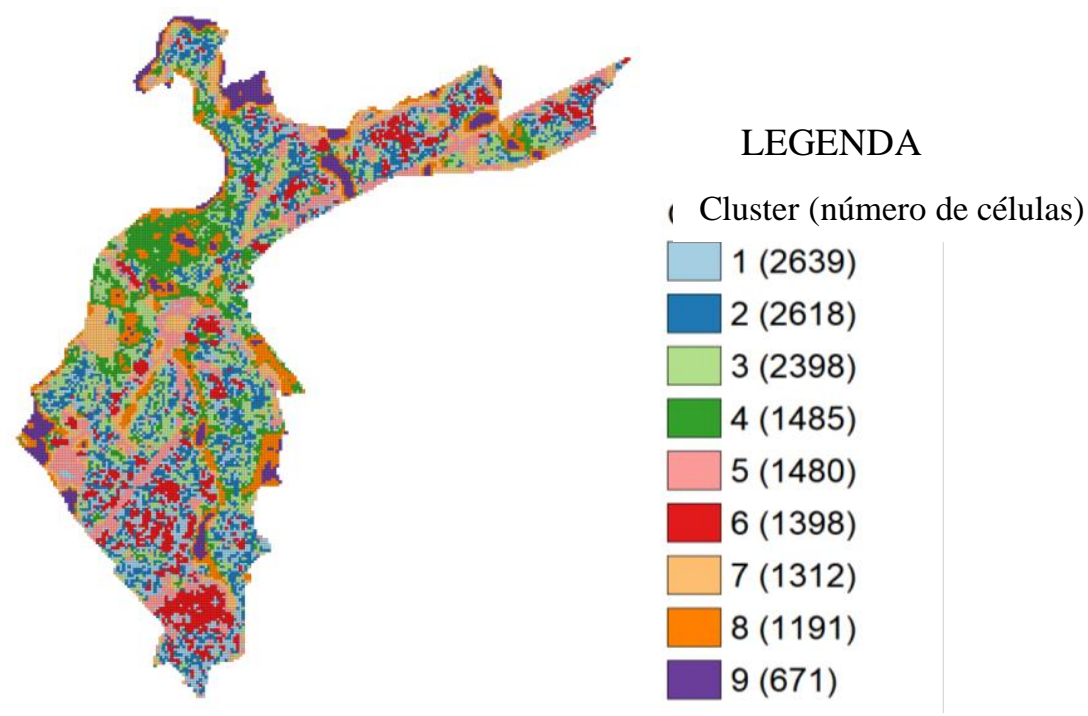


Figura 15 - TS $\left({ }^{\circ} \mathrm{C}\right)$ para 9 clusters

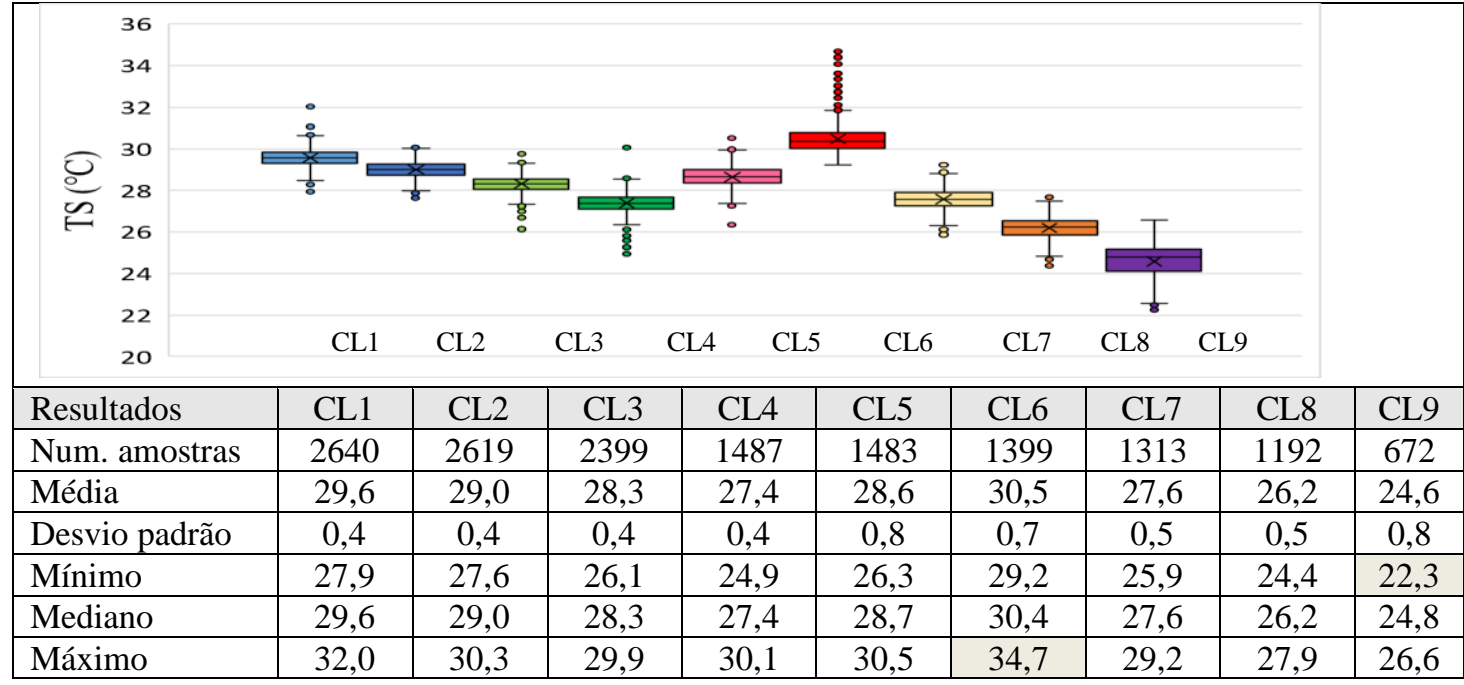

Figura 16 - FCV (\%) para 9 clusters

\begin{tabular}{|c|c|c|c|c|c|c|c|c|c|}
\hline $\begin{array}{l}90 \\
80\end{array}$ & & & & & & & 7 & & \\
\hline 70 & & & 0 & & & & & & \\
\hline (2 60 & & 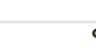 & : & & & & & & \\
\hline e 50 & & & & : & & & X & & \\
\hline 己 40 & 0 & & & & - & & & & \\
\hline 工 30 & & & & & • & & & & \\
\hline 10 & & & & $x$ & $\bullet$ & & & & \\
\hline 0 & CL1 & CL2 & & CL & $\overline{\mathrm{CL}} 6$ & CL7 & CL8 है & & \\
\hline Resultados & CL1 & CL2 & CL3 & CL4 & CL5 & CL6 & CL7 & CL8 & CL9 \\
\hline Num. amostras & 2640 & 2619 & 2399 & 1486 & 1481 & 1399 & 1313 & 1192 & 672 \\
\hline Média & 2,2 & 3,8 & 7,7 & 12,8 & 13,4 & 1,0 & 22,8 & 29,9 & 52,6 \\
\hline Desvio padrão & 3,1 & 3,6 & 7,2 & 10,9 & 10,3 & 1,6 & 13,4 & 18,2 & 19,0 \\
\hline Mínimo & 0,0 & 0,0 & 0,1 & 0,1 & 0,1 & 0,0 & 0,1 & 0,3 & 0,6 \\
\hline Mediano & 1,4 & 2,6 & 5,3 & 9,5 & 10,9 & 0,7 & 22,4 & 29,0 & 55,5 \\
\hline Máximo & 40,0 & 35,1 & 57,0 & 64,7 & 54,6 & 38,3 & 67,1 & 77,5 & 85,0 \\
\hline
\end{tabular}

Figura 17 - Albedo (\%) para 9 clusters

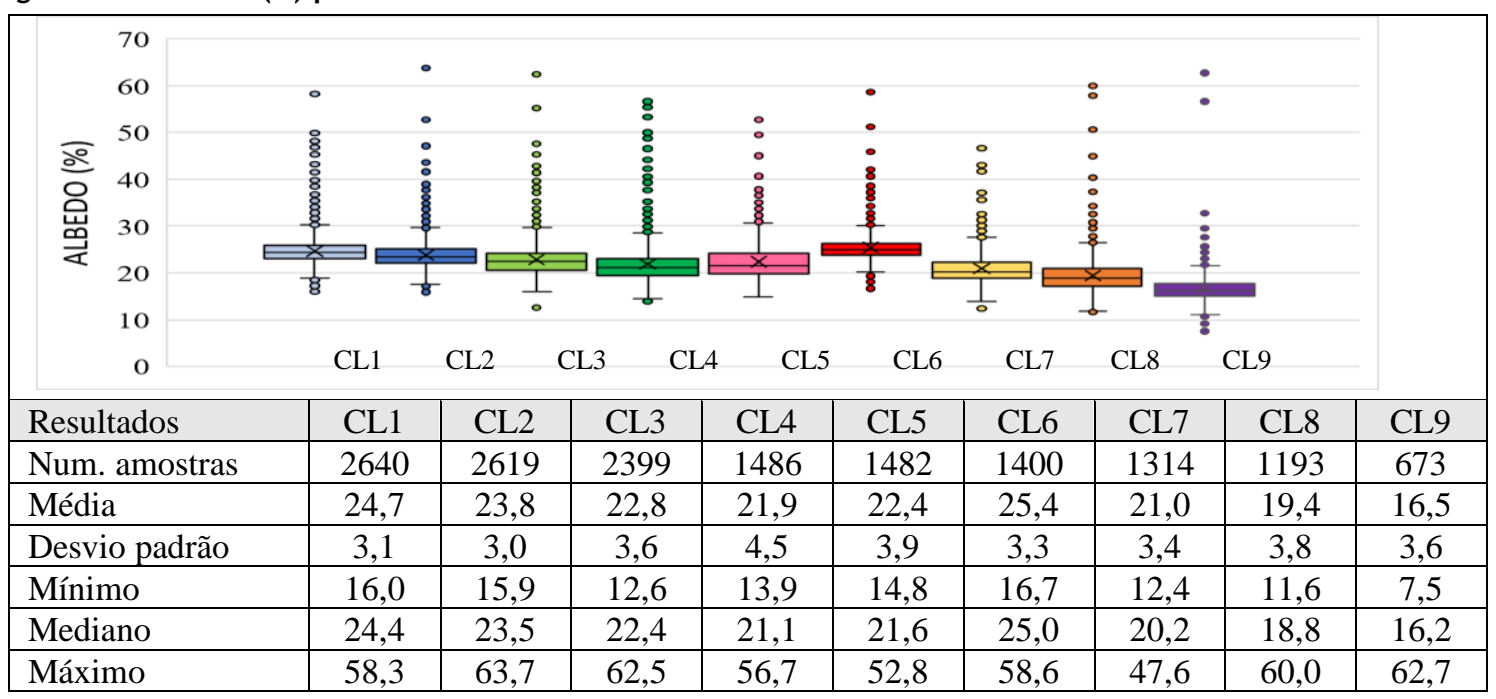


Figura 18 - Emissividade para 9 clusters

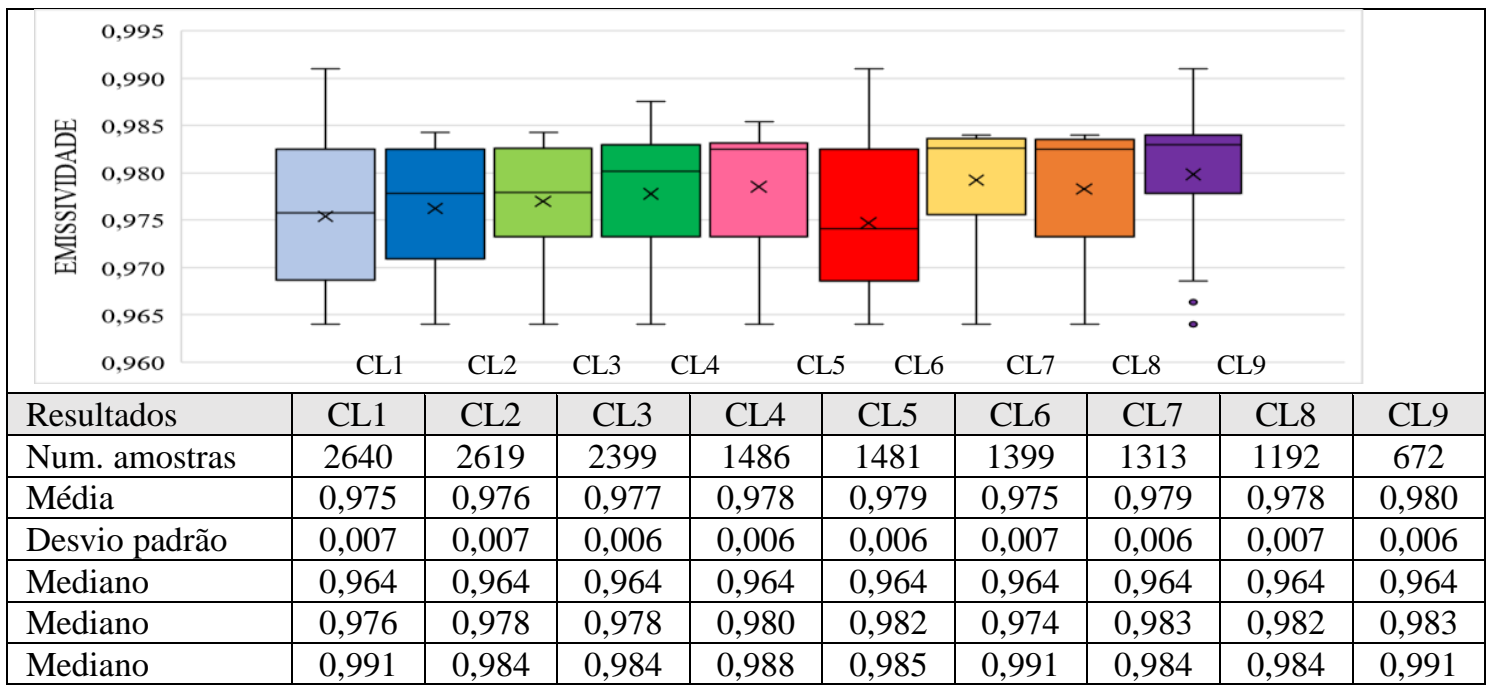

Figura 19 - NDMI para 9 clusters

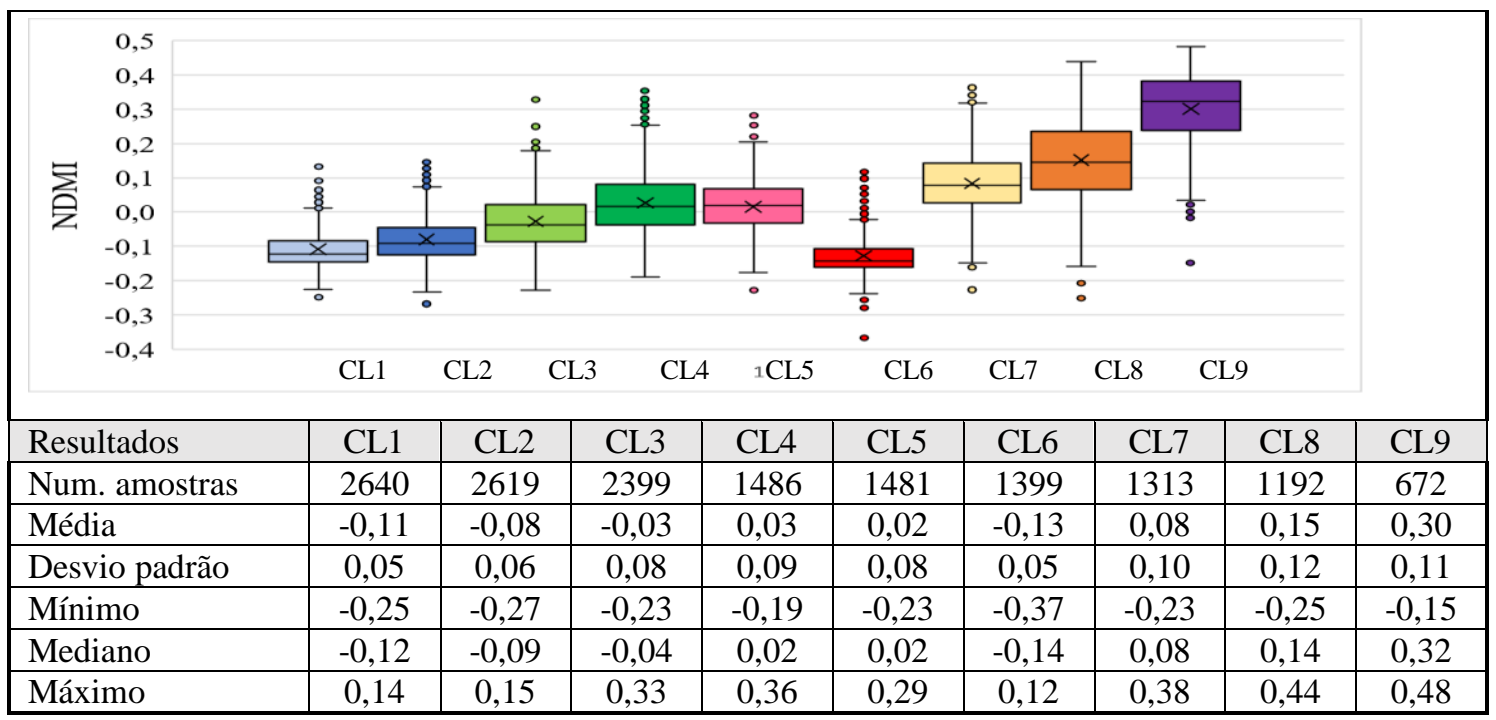

O mapeamento da área de estudos em 9 clusters identificou 11 ZCL presentes na macrozona de consolidação: ZCL1, 2, 3, 4, 6, 8, 9, A, B, D e E. O gráfico da Figura 20 resume os valores obtidos para cada cluster, bem como a ZCL associada.

As ZCLs identificadas nos dois clusters mais quentes (CL6 e CL1) foram a ZCL3 associada à ZCL2 $\left(Z_{C L}\right)$ e ZCL8 associada à ZCLE (ZCL8E). No CL6, o mais quente, observa-se a presença de áreas densamente ocupadas por construções horizontais de pequeno e médio porte $\left(\right.$ ZCL3 $\left._{2}\right)$ e áreas ocupadas por grandes centros comerciais e amplos estacionamentos, com pouca ou nenhuma vegetação (ZCL8E) (Figura 21). No CL1 observa-se a presença das $\mathrm{ZCL}_{2}$ (Figura 22). Esses clusters resultaram nos menores valores de $\varepsilon$, NDMI e FCV observados para toda a MC, e nos maiores A, resultado da ausência de árvores e sombras, com predominância de áreas construídas e impermeáveis similares aos da ZCLE, com área impermeável > $90 \%$.

As ZCL observadas nos dois cluster mais frios (CL9 e CL8) foram as ZCLA, ZCLB, ZCL4, ZCL6 e ZC9. No CL9, o cluster mais frio, observa-se a predominância de áreas densamente arborizadas (ZCLA) e áreas com árvores esparsas (ZCLB) (Figura 23). No CL8 observa-se a ZCL4, composta por áreas ocupadas por construções esparsas e verticais de grande porte intercaladas por vegetação e ZCL6 com construções esparsas de pequeno porte intercaladas por vegetação (Figura 24). O CL9 e o CL8 obtiveram os maiores valores de $\varepsilon$, NDMI e FCV de todo conjunto de dados, e os menores valores de A, resultado da presença de 
vegetação. Nesses clusters destacam-se a presença de árvores, áreas permeáveis e sombras naturais, produzidas pelas árvores, e artificiais, produzidas por prédios.

As ZCLs identificadas no CL2 e CL3 foram as associações entre a ZCL3, ZCL1 e ZCL2 (ZCL3 1-2) (Figuras 25 e 26). A ZCL1 caracteriza-se pela presença de edificações verticais de grande porte, e a ZCL2 por edificações compactas de médio porte.

Figura 20 - Clusters, ZCL e características espectrais

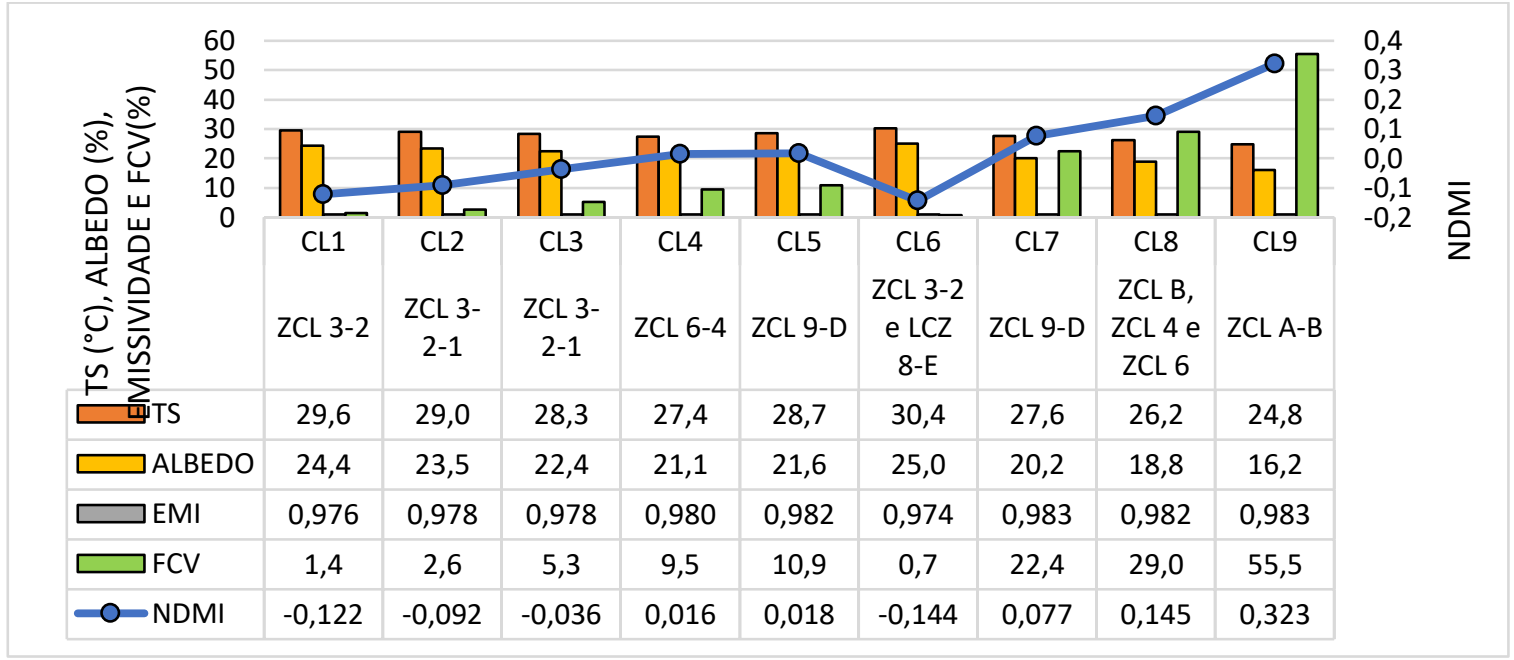

Figura 21 - CL6: ZCL32 (a) e ZCL8E (b)

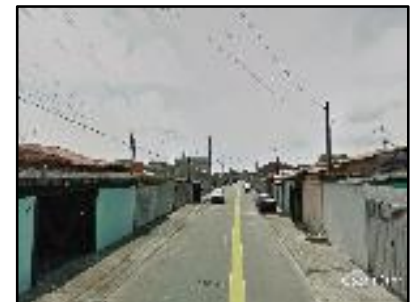

(a)

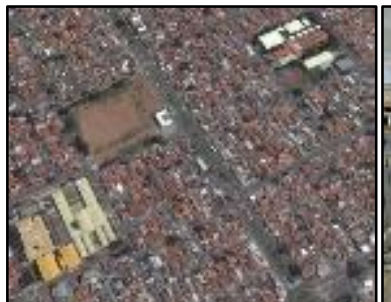

(a)

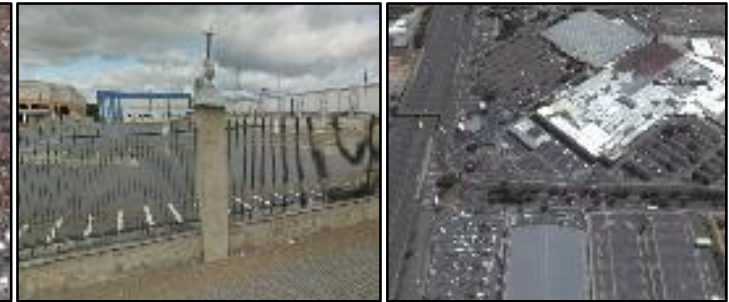

(b)

(b)

Figura 22 - CL1: ZCL32
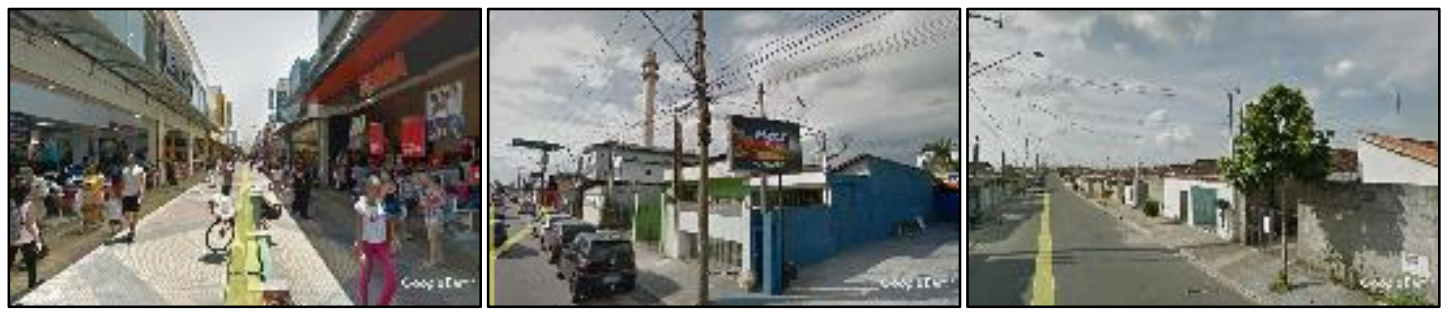

Figura 23 - CL9: ZCLA (a) e ZCLB (b)

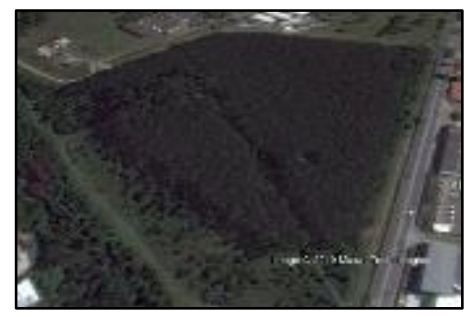

(a)

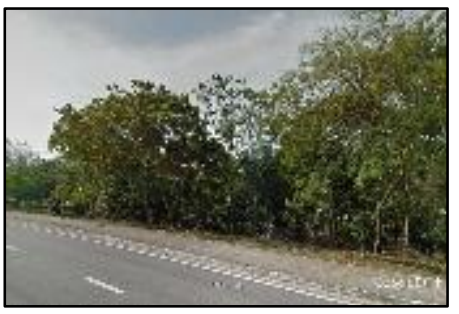

(b)

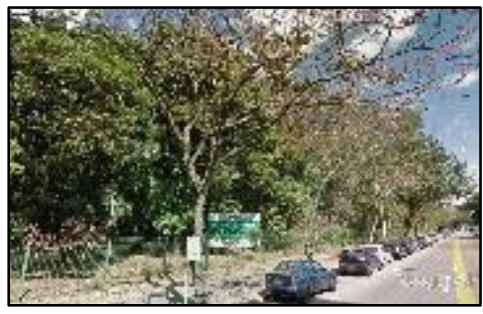

(b)

256 Ferreira, F. L. e S.; Pereira, E. B.; Labaki, L. C. 
Figura 24 - CL8: ZCL4 (a), ZCL6 (b) e ZCL9 (c)

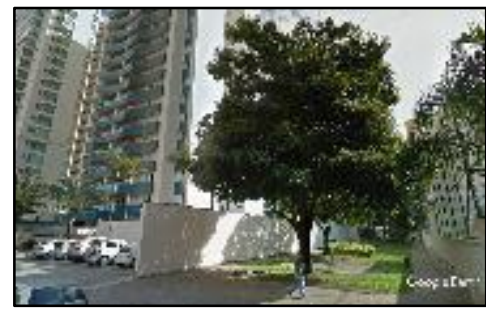

(a)

Figura 25 - CL2: ZCL31-2

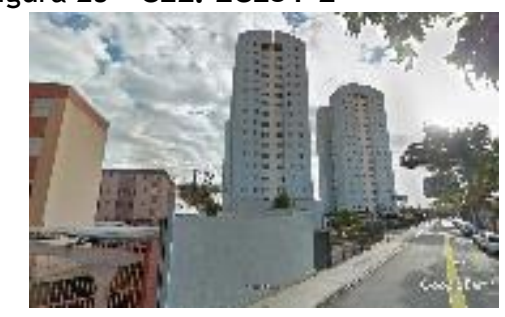

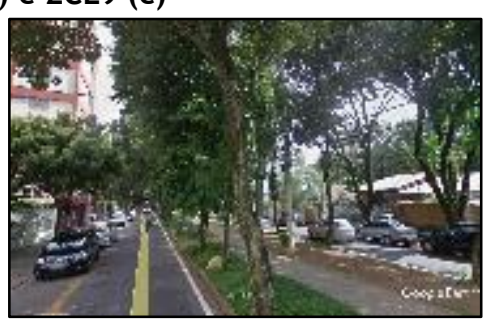

(b)

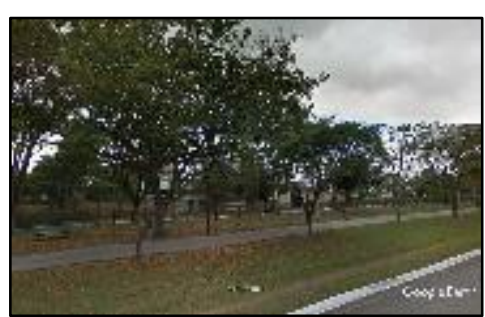

(c)

Figura 26 - CL3: ZCL31-2
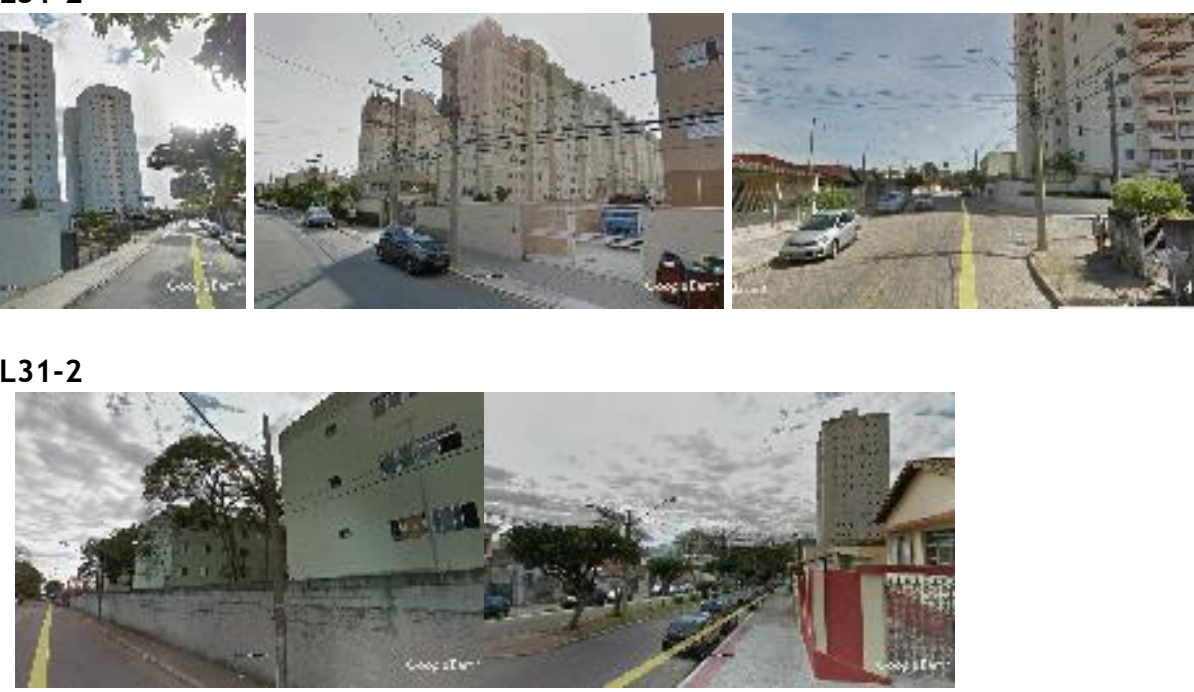

No CL4 foram identificadas associações entre a ZCL6 e ZCL4 (ZCL64). Nesse cluster observa-se a ocorrência de vegetação de porte arbóreo, áreas permeáveis e sombras produzidas por arvores e por prédios (Figura 27).

As ZCL identificadas nos clusters CL5 e CL7 foram: a ZCL9, caracterizada por áreas com construções esparsas e ZCLD, caracterizadas por áreas com predominância de vegetação rasteira (ZCL9 $\mathrm{D})$. Esses clusters correspondem a áreas destinadas ao sistema viário urbano ou em processo de urbanização (Figura ).

A maior diferença de TS entre clusters ocorreu entre o CL6 $\left(30^{\circ} \mathrm{C}\right)$ e o CL9 $\left(25^{\circ} \mathrm{C}\right)$, cuja diferença entre os valores medianos de TS foi de aproximadamente $5{ }^{\circ} \mathrm{C}$, ultrapassando $12{ }^{\circ} \mathrm{C}$ em áreas onde foram identificadas as menores e as maiores TS (Figura 15). As áreas do CL6 obtiveram os menores valores de NDMI $(-0,14)$, FCV $(0,7 \%)$ e emissividade $(0,974)$ da MC. As áreas do CL9 mostraram os maiores NDMI $(0,32), \operatorname{FCV}(55,48 \%)$ e emissividade $(0,984)$.

O mapeamento de clusters de TS e a classificação das áreas urbanas em ZCLs permitiram identificar áreas, classificadas como clusters diferentes, mas com a mesma classificação de ZCL (Figura 29). Os resultados do mapeamento apontam que aproximadamente $59 \%$ da área da macrozona de consolidação urbana de SJC é predominantemente ocupada por edificações esparsas de pequeno porte (ZCL3), 18\% por construções esparsas associadas à vegetação $(Z C L 9 \mathrm{D}), 18 \%$ por edificações de pequeno e grande porte intercaladas por vegetação (ZCL6 e ZCL4), $4 \%$ por vegetação de porte arbóreo (ZCLA $\left.{ }_{B}\right)$ e $2 \%$ por construções extensas em áreas plenamente impermeabilizadas (ZCL8E).

A identificação das tipologias construtivas, onde a ZCL3 é predominante, e onde ocorrem a ZCL4 e ZCL6, permite inferir que o decaimento da TS ocorre em função da verticalização das construções, associada à vegetação, e onde áreas permeáveis se fazem presentes, podendo esse efeito ser observado nos dados compilados da Figura 30.

A influência da presença de vegetação de porte arbóreo e de sombra também se mostra evidente nas análises dos resultados do CL5 e CL7, onde se observa a ZCL9 . Se no CL5 as construções esparsas do sistema viário estão associadas à vegetação rasteira, no CL7 já se observa a presença de vegetação de porte arbóreo, ou a predominância de áreas verdes, o que resulta em uma menor TS (CL5(A) e CL7(B):ZCL9D, Figura 28). 
Figura 27 - CL4: ZCL64

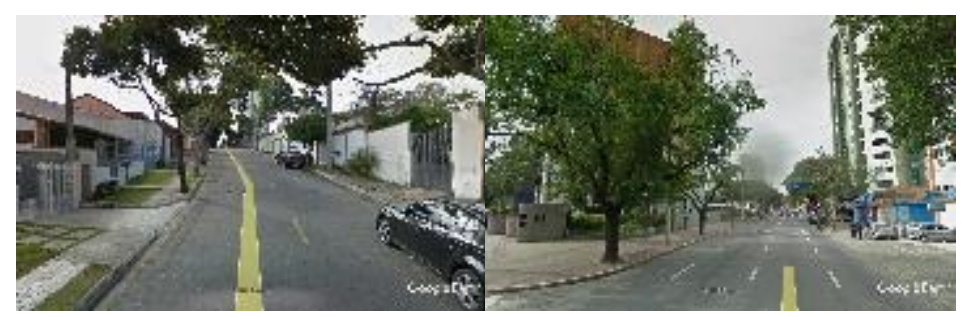

Figura 28 - CL5 (a) e CL7 (b): ZCL9D

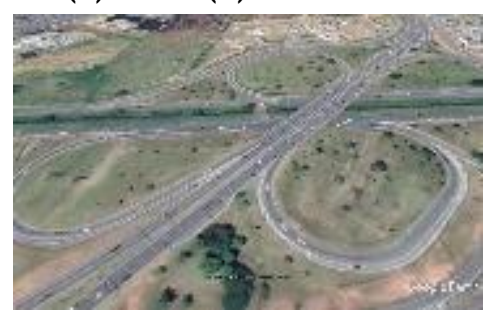

(a)

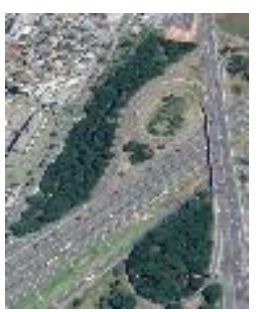

(b)

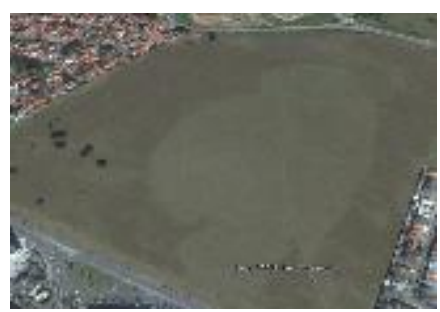

(b)

Figura 29 - ZCL na macrozona de consolidação de SJC
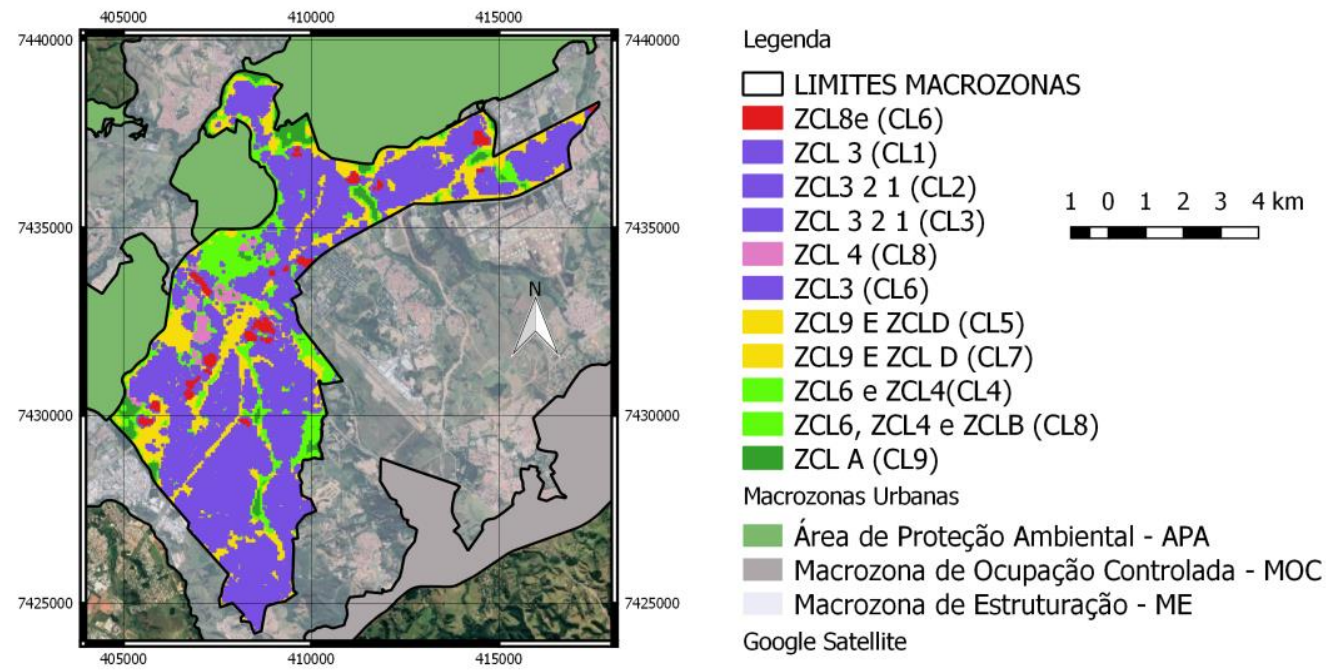

Figura 30 - Variação da TS associada à verticalização, presença de umidade e FCV

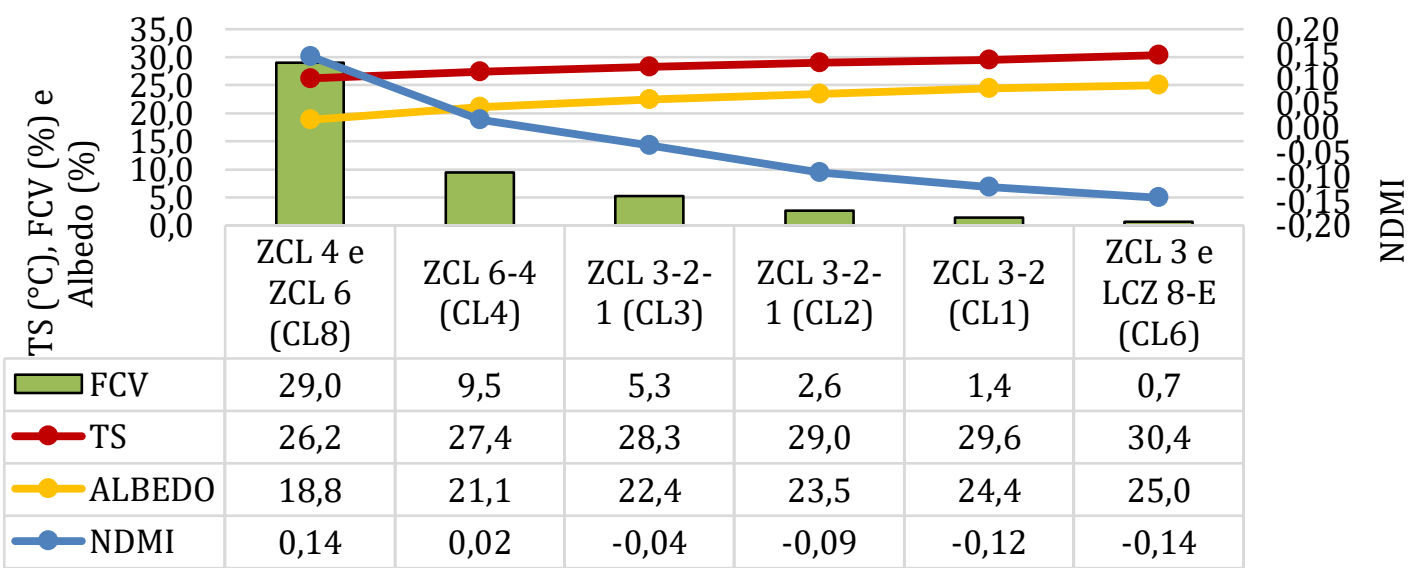


Os resultados obtidos para os 4 clusters que apresentaram as menores TS na MC (CL9, CL8, CL7 e CL4) apontam que a tendência de resfriamento das superfícies, no período diurno, está associada aos processos de sombreamento e em função da presença de água ou umidade na superfície. O sombreamento promove a atenuação da radiação solar incidente, minimizando o ganho de calor nas superfícies e pode ocorrer naturalmente, dada a presença de árvores ou artificialmente, em função da presença de construções verticalizadas, quando associadas às áreas verdes. A umidade, associada à presença de vegetação e áreas permeáveis auxilia na ocorrência dos fluxos de calor latente, que processam o calor retido na superfície. Os resultados obtidos para os clusters mais quentes (CL6, CL1, CL2, CL3 e CL5) apontam que os processos de aquecimento estão associados à ausência de umidade, vegetação e sombra, em áreas predominantemente impermeabilizadas.

A análise dos clusters confirma os resultados obtidos nas análises de correlação, que apontam que baixas TS estão associadas à alta emissividade, presença de água e vegetação, e baixo albedo. Os resultados refletem as características termofísicas das superfícies na escala urbana, composta por superfícies heterogêneas, onde vegetação e área construída ocorrem em paralelo, e para as quais quanto maior o FCV detectado na célula, maior a absorção de radiação solar visível e menor o A.

\section{Considerações finais}

A integração de informações georreferenciadas em uma grade regular ou espaço celular, criada a partir da discretização de zonas urbanas em células de $60 \mathrm{~m}$ x $60 \mathrm{~m}$, mostrou-se eficaz para a produção de informações, em alta resolução espacial, que podem ser utilizadas para produzir diagnósticos na escala local, micro ou macro climática, dependendo do número de células agrupadas. O procedimento pode auxiliar em parametrizações e identificação de áreas vulneráveis e prioritárias, para as quais se fazem necessárias intervenções pontuais.

O uso de imagens de satélite, como as do L8-L2, que representam um momento no tempo-espaço, possibilita identificar tendências e padrões que determinam o comportamento térmico e energético das superfícies urbanas, o que é extremamente útil no desenvolvimento de benchmarking para o planejamento urbano voltado para promover a resiliência e adaptação urbana ao calor.

Nesta pesquisa, os índices de autocorrelação espacial de Moran acima de 0,65 permitiram inferir a dependência espacial TS, independente da variabilidade climática sazonal, o que facilita na compreensão da dinâmica sócio espacial que influencia a consolidação do tecido urbano. Os coeficientes de correlação de Spearman, obtidos entre TS e as variáveis espectrais, mostraram que a redução da TS está diretamente relacionada ao aumento do FCV, $\mathcal{E}$ e NDMI, e que a correlação entre A e TS é afetada pela presença de vegetação na célula, devendo-se considerar essa relação na interpretação dos resultados.

As análises de clusters apontam que as maiores diferenças de TS ocorreram em áreas classificadas como CL6 e CL9 e chegou a $12{ }^{\circ} \mathrm{C}$. A análise dos resultados obtidos para cada cluster permitiu inferir que os efeitos de retroalimentação negativos, que produzem o resfriamento das superfícies urbanas, estão associados à presença de áreas permeáveis, detectadas pela presença de umidade, vegetação e sombra. As áreas de sombra, produzidas naturalmente por árvores ou artificialmente por prédios, contribuem para a atenuação do impacto da incidência da radiação solar no ganho de calor em superfícies no período diurno, resultando na diminuição da absorção e armazenamento de calor pelas estruturas urbanas, que influenciam as temperaturas no período noturno. O efeito de resfriamento das superfícies pode ser amplificado pelo uso de edificações associadas às áreas arborizadas e permeáveis. Essa conclusão foi possível a partir da observação dos resultados obtidos para os CL8 e CL4, onde se observa a ocorrência da ZCL 4.

Os resultados permitem inferir que as intervenções no tecido urbano, voltadas para promover a resiliência urbana ao calor, produzindo o efeito de retroalimentação negativa do sistema climático urbano, que podem ser utilizadas como tecnologias solares passivas, devem se concentrar em duas grandes frentes:

(a) priorizar a implantação e a recuperação de áreas permeáveis e verdes, dentro e fora dos lotes; e

(b) ampliar as áreas de sombra por processos de arborização ou incentivo à verticalização de construções desde que associadas a áreas verdes e permeáveis.

Nesse sentido, conclui-se que o mapeamento da temperatura das superfícies permite identificar as tipologias construtivas, que influenciam os processos de retroalimentação negativa e positiva do sistema climático urbano e ZCLs associadas. Esse procedimento pode auxiliar no desenvolvimento de políticas voltadas para 
promover a adaptação e a resiliência urbana ao calor, o que é extremamente útil para o desenvolvimento de benchmarking para o planejamento do tecido urbano.

Como trabalhos futuros sugere-se:

(a) aplicar o método em outras áreas urbanas consolidadas, para avaliar o desempenho térmico e energético das zonas climáticas locais, sob diferentes condições climáticas;

(b) acoplar os resultados às características sociais e econômicas dos municípios, e

(c) investigar a eficiência de diferentes fatores de forma em diferentes condições climáticas.

\section{Referências}

AKBARI, H. et al. Local climate change and urban heat island mitigation techniques: the state of the art. Journal of Civil Engineering and Management, v. 22, n. 1, p. 1-16, dez. 2015.

ALLEN, M. R.; DUBE, O. P.; SOLECKI, W. IPCC 2018 report: global warming of $1.5^{\circ}$ C. 2018. Disponível em: https://www.ipcc.ch/site/assets/uploads/sites/2/2019/05/SR15_Chapter1_Low_Res.pdf. Acesso em: 2 set. 2019.

ANSELIN, L. Exploring spatial data with GeoDa TM : a workbook center for spatially integrated social science. University of Illinois: Center for Spatially Integrated Social Science, 2005. Disponível em: http://sal.uiuc.edu/http://www.csiss.org/. Acesso em: 22 ago. 2019.

ANSELIN, L. Local Indicators of Spatial Association-LISA. Geographical Analysis, v. 27, n. 2, p. 93-115, set. 2010.

ARTIS, D. A.; CARNAHAN, W. H. Survey of emissivity variability in thermography of urban areas. Remote Sensing of Environment, v. 12, n. 4, p. 313-329, set. 1982.

ASSOCIAÇÃO BRASILEIRA DE NORMAS TÉCNICAS. NBR 15220: desempenho térmico de edificações. Rio de Janeiro, 2005.

BAZAZ, A. et al. Summary for urban policymakers: what the IPCC special report on $1.5 \mathrm{C}$ means for cities. IIHS. Disponível em: http://doi.org/10.24943/SCPM.2018. Acesso em: 18 fev. 2019.

CARLSON, T. N.; RIPLEY, D. A. On the relation between NDVI, fractional vegetation cover, and leaf area index. Remote Sensing of Environment, v. 62, n. 3, p. 241-252, dez. 1997.

CHUVIECO, E.; HUETE, A. Fundamentals of satellite remote sensing. New York: CRC Press, 2010.

COMPANHIA AMBIENTAL DO ESTADO DE SÃO PAULO. Serviços - CETESB. Disponível em: https://cetesb.sp.gov.br/ar/qualar/. Acesso em: 15 fev. 2019.

COMPANHIA AMBIENTAL DO ESTADO DE SÃO PAULO. Serviços. Disponível em:

http://qualar.cetesb.sp.gov.br/qualar/conDadosHorarios.do?method=gerarRelatorio. Acesso em: 29 out. 2018.

DRUCK, S. et al. Análise espacial de dados geográficos. Brasília: Embrapa Cerrados, 2004.

FERNANDES, R. B. A. et al. Quantificação de óxidos de ferro de latossolos brasileiros por espectroscopia de refletância difusa. Revista Brasileira de Ciência do Solo, v. 28, n. 2, p. 245-257, 2004.

GEODA. Documentation. Disponível em: http://geodacenter.github.io/documentation.html. Acesso em: 10 fev. 2019.

GLOBAL COOL CITIES ALLIANCE. A practical guide to cool roofs and cool pavements. Disponível em: https://www.coolrooftoolkit.org/wp-content/pdfs/CoolRoofToolkit_Full.pdf. Acesso em: 5 ago. 2019.

GLOBAL ENERGY ASSESSMENT. Toward a sustainable future. Laxenburg. Disponível em: http://www.iiasa.ac.at/Research/ENE/GEA/. Acesso em: 15 out. 2020.

GOOGLE EARTH. [Mapa]. Disponível em: https://www.google.com.br/earth/index.html. Acesso em: 25 abr. 2019.

INSTITUTO BRASILEIRO DE GEOGRAFIA E ESTATÍSTICA. Brasil em síntese: São Paulo: São José dos Campos: panorama. Disponível em: https://cidades.ibge.gov.br/brasil/sp/sao-jose-doscampos/panorama. Acesso em: 4 fev. 2019a.

260 Ferreira, F. L. e S.; Pereira, E. B.; Labaki, L. C. 
INSTITUTO BRASILEIRO DE GEOGRAFIA E ESTATÍSTICA. Downloads: geociências. Disponível em: https://downloads.ibge.gov.br/downloads_geociencias.htm. Acesso em: 13 abr. 2019b.

INSTITUTO NACIONAL DE PESQUISAS ESPACIAIS. FillCell - Luccme. Disponível em: http://luccme.ccst.inpe.br/fillcell/. Acesso em: 22 ago. 2018.

INTERNATIONAL ENERGY AGENCY. Data \&amp; Statistics - IEA. Disponível em: https://www.iea.org/data-and-statistics?country=WORLD\&fuel=Energy consumption \& indicator=Coal final consumption by sector. Acesso em: 21 mar. 2020.

JIN, M. et al. A practical split-window algorithm for retrieving land surface temperature from Landsat-8 data and a case study of an urban area in China. Remote Sensing, v. 7, n. 4, p. 4371-4390, abr. 2015.

LUCON, O. et al. Buildings. Disponível em: https://www.ipcc.ch/pdf/assessmentreport/ar5/wg3/ipcc_wg3_ar5_chapter9.pdf. Acesso em: 8 ago. 2018.

MARÔCO, J. Análise estatística com utilização do SPSS. 3. ed. Lisboa: Sílabo. 2007.

MCGUFFIE, K.; HENDERSON-SELLERS, A. A climate modelling primer. Chichester: John Wiley \& Sons, 2014.

MOITA, F. Energia solar passiva. 2. ed. Lisboa: Argumentum, 2010.

OKE, T. R. The energetic basis of the urban heat island. Quarterly Journal of the Royal Meteorological Society, v. 108, n. 455, p. 1-24, 1982.

PRADO, R. T. A.; FERREIRA, F. L. Measurement of albedo and analysis of its influence the surface temperature of building roof materials. Energy and Buildings, v. 37, n. 4, p. 295-300, abr. 2005.

QGIS. QGIS 2.18.27. Las Palmas, 2017. Disponível em: http://qgis.osgeo.org. Acesso em: 4 nov. 2017.

QI, J.-D. et al. Do grey infrastructures always elevate urban temperature? no, utilizing grey infrastructures to mitigate urban heat island effects. Sustainable Cities and Society, v. 46, p. 101392, abr. 2019.

REDEMET. Sistema de Geração e Disponibilização de Informações Climatológicas. Disponível em: http://clima.icea.gov.br/clima/tempMHMS.php. Acesso em: 22 ago. 2018

RSTUDIO. Home: RStudio. 2015. Disponível em: https://www.rstudio.com/. Acesso em: 22 ago. 2018.

SÃO JOSÉ DOS CAMPOS. Geoprocessamento. Disponível em:

http://www.sjc.sp.gov.br/servicos/urbanismo-e-sustentabilidade/uso-do-solo/geoprocessamento/. Acesso em: 13 abr. 2019a.

SÃO JOSÉ DOS CAMPOS. Plano diretor de São José dos Campos - SP. Disponível em: https://leismunicipais.com.br/plano-diretor-sao-jose-dos-campos-sp. Acesso em: 4 fev. 2019b.

SOBRINO, J. A. et al. Land surface emissivity retrieval from different VNIR and TIR sensors. IEEE Transactions on Geoscience and Remote Sensing, v. 46, n. 2, p. 316-327, fev. 2008.

SOBRINO, J. A.; CASELLES, V.; BECKER, F. Significance of the remotely sensed termal infrared measurements obtained over a citrus orchard. Journal of Photogrammetry and Remote Sensing, v. 44, n. 6, p. 343-354, mar. 1990.

SOBRINO, J. A.; RAISSOUNI, N. Toward remote sensing methods for land cover dynamic monitoring: application to Morocco. International Journal of Remote Sensing, v. 21, n. 2, p. 353-366, jan. 2000.

STEWART, I. D.; OKE, T. R. Local climate zones for urban temperature studies. Bulletin of the American Meteorological Society, v. 93, n. 12, p. 1879-1900, 2012.

STEWART, I. D.; OKE, T. R.; KRAYENHOFF, E. S. Evaluation of the 'local climate zone' scheme using temperature observations and model simulations. International Journal of Climatology, v. 34, n. 4, p. 1062-1080, mar. 2014.

TASUMI, M.; ALLEN, R. G.; TREZZA, R. At-surface reflectance and Albedo from satellite for operational calculation of land surface energy balance. Journal of Hydrologic Engineering, v. 13, n. 2, p. 51-63, fev. 2008.

TOBLER, W. R. Cellular geography. In: GALE, S.; OLSSON, G. (ed.). Philosophy in Geography. Dordrecht: D Reidel Publishing Company, 1979. 
UNITED STATES GEOLOGICAL SURVEY. EarthExplorer: home. Disponível em: https://earthexplorer.usgs.gov/. Acesso em: 22 ago. 2019a.

UNITED STATES GEOLOGICAL SURVEY. ESPA - LSRD. Disponível em: https://espa.cr.usgs.gov/. Acesso em: 17 dez. 2019b.

UNITED STATES GEOLOGICAL SURVEY. Landsat Data Access. Disponível em: https://www.usgs.gov/land-resources/nli/landsat/landsat-data-access?qtscience_support_page_related_con=0\#qt-science_support_page_related_con. Acesso em: $17 \mathrm{dez} .2019 \mathrm{c}$. UPTON, G. J. G.; COOK, I. Understanding statistics. Oxford: Oxford University Press, 1996.

URBANIZATION AND DEVELOPMENT Emerging futures. World cities report, 2016. Naiorobi. Disponível em: https://unhabitat.org/sites/default/files/download-manager-files/WCR-2016-WEB.pdf. Acesso em: 1 fev. 2020.

VERBURG, P. H. et al. A spatial explicit allocation procedure for modelling the pattern of land use change based upon actual land use. Ecological Modelling, v. 116, p. 45-61, 1999.

VERMOTE, E. et al. Preliminary analysis of the performance of the Landsat 8/OLI land surface reflectance product. Remote Sensing of Environment, v. 185, p. 46-56, nov. 2016.

WALSH, A.; CÓSTOLA, D.; LABAKI, L. C. Review of methods for climatic zoning for building energy efficiency programs. Building and Environment, v. 112, p. 337-350, 2017.

WATERS, R. et al. SEBAL Surface Energy Balance Algorithms for Land: idaho implementation advanced training and users manual. NASA, 2002. Disponível em: http://www.posmet.ufv.br/wpcontent/uploads/2016/09/MET-479-Waters-et-al-SEBAL.pdf. Acesso em: 23 out. 2018.

ZANTER, K. LANDSAT 8 (L8) DATA USERS HANDBOOK Version 4.0 April 2019Department of the Interior, U.S. Geological Survey. Disponível em: https://www.usgs.gov/media/files/landsat-8-datausers-handbook. Acesso em: 23 out. 2018.

\title{
Agradecimentos
}

Agradecimentos a Capes pela bolsa de pesquisa de doutorado, ao Instituto Nacional de Pesquisas Espaciais (Inpe) e ao Laboratório de Modelagem e Estudos de Recursos Renováveis de Energia (LABRENabren), locado na Divisão de Impactos, Adaptação e Vulnerabilidadeso Centro de Ciência do Sistema Terrestre (CCST). Este trabalho é uma contribuição do Instituto Nacional de Ciência e Tecnologia para Mudanças Climáticas (INCT-MC), financiado pela FAPESP 2014/50848-9, CNPq 465501/2014-1, e CAPES/FAPS n ${ }^{\circ}$ $16 / 2014$.

Fabiana Lourenço e Silva Ferreira

Divisão de Impactos, Adaptação e Vulnerabilidades | Instituto Nacional de Pesquisas Espaciais | Av. dos Astronautas, Jardim da Granja | São José dos Campos - SP - Brasil | CEP 12227-010 | Tel.: (12) 99765-0109 | E-mail: fabianalou@hotmail.com

Enio Bueno Pereira

Divisão de Impactos, Adaptação e Vulnerabilidades | Instituto Nacional de Pesquisas Espaciais | Tel.: (12) 3208-7786 | E-mail: enio.pereira@inpe.br

\section{Lucila Chebel Labaki}

Departamento de Arquitetura e Construção Faculdade de Engenharia Civil, Arquitetura e Urbanismo | Universidade Estadual de Campinas | Rua Saturnino de Brito, 224, Cidade Universitária Zeferino Vaz Barão Geraldo | Campinas - SP - Brasil | CEP 13083-889 | Tel.: (19) 35212309 | E-mail: lucila@fec.unicamp.br

\author{
Ambiente Construído \\ Revista da Associação Nacional de Tecnologia do Ambiente Construído \\ Av. Osvaldo Aranha, $99-3^{\circ}$ andar, Centro \\ Porto Alegre - RS - Brasil \\ CEP 90035-190 \\ Telefone: +55 (51) 3308-4084 \\ Fax: +55 (51) 3308-4054 \\ www.seer.ufrgs.br/ambienteconstruido \\ E-mail: ambienteconstruido@ufrgs.br
}

